\title{
Anti-CXCR4 Single-Chain Variable Fragment Antibodies Have Anti-Tumor Activity
}

\author{
Guang-Quan Liang ${ }^{1 \dagger}$, Jing Liu ${ }^{1 \dagger}$, Xiao-Xin Zhou ${ }^{1 \dagger}$, Ze-Xiong Lin ${ }^{1}$, Tao Chen ${ }^{1}$, Guo Chen ${ }^{2 *}$ \\ and Henry Wei ${ }^{\text {1* }}$ \\ ${ }^{1}$ Department of Cell Biology and Institute of Biomedicine, Guangdong Provincial Key Laboratory of Bioengineering Medicine, \\ Guangdong Provincial Biotechnology Drug and Engineering Technology Research Center, National Engineering Research \\ Center of Genetic Medicine, College of Life Science and Technology, Jinan University, Guangzhou, China, ${ }^{2}$ Department of \\ Medical Biochemistry and Molecular Biology, School of Medicine, Jinan University, Guangzhou, China
}

OPEN ACCESS

Edited by: Kwong Tsang,

Precision Biologics, Inc., United States

Reviewed by:

Pierpaolo Correale, Azienda ospedaliera 'BianchiMelacrino-Morelli', Italy

Massimo Fantini,

Precision Biologics, Inc.,

United States

*Correspondence: Henry Wei 2217260762@qq.com Guo Chen

gchen84@jnu.edu.cn

${ }^{\dagger}$ These authors have contributed equally to this work

Specialty section:

This article was submitted to Cancer Molecular Targets and Therapeutics, a section of the journa

Frontiers in Oncology

Received: 10 June 2020 Accepted: 24 November 2020 Published: 18 December 2020

Citation: Liang G-Q, Liu J, Zhou X-X, Lin Z-X, Chen T, Chen $G$ and Wei $H$ (2020) Anti-CXCR4 Single-Chain Variable

Fragment Antibodies Have Anti-Tumor Activity.

Front. Oncol. 10:571194. doi: 10.3389/fonc.2020.571194
Monoclonal antibodies (mAbs) are large and have limitations as cancer therapeutics. Human single-chain variable fragment (scFv) is a small antibody as a good alternative. It can easily enter cancer tissues, has no immunogenicity and can be produced in bacteria to decrease the cost. The chemokine receptor CXCR4 is overexpressed in different cancer cells. It plays an important role in tumor growth and metastasis. Its overexpression is associated with poor prognosis in cancer patients and is regarded as an attractive target for cancer treatment. In this study, a peptide on the CXCR4 extracellular loop 2 (ECL2) was used as an antigen for screening a human scFv antibody library by yeast twohybrid method. Three anti-CXCR4 scFv antibodies were isolated. They could bind to CXCR4 protein and three cancer cell lines (DU145, PC3, and MDA-MB-231) and not to 293T and 3T3 cells as negative controls. These three scFvs could decrease the proliferation, migration, and invasion of these cancer cells and promote their apoptosis. The two scFvs were further examined in a mouse xenograft model, and they inhibited the tumor growth. Tumor immunohistochemistry also demonstrated that the two scFvs decreased cancer cell proliferation and tumor angiogenesis and increased their apoptosis. These results show that these anti-CXCR4 scFvs can decrease cancer cell proliferation and inhibit tumor growth in mice, and may provide therapy for various cancers.

Keywords: CXCR4, scFv, cancer, antibody, yeast two-hybrid

\section{INTRODUCTION}

Chemokines belong to a large family of soluble chemotactic cytokines that bind to G proteincoupled receptors (GPCRs) to cause a cellular response, such as cell migration and adhesion (1). They can be divided into inflammatory and homeostatic chemokines according to their functions. About 50 human chemokines and nearly 20 their receptors have been identified and characterized since the discovery of the first chemotactic cytokine interleukin 8 (IL-8) $(2,3)$. Chemokines and their receptors play an important role in inflammation, infection, cardiovascular disease and cancer development. The chemokine receptor CXCR4 is a GPCR and consists of 352 amino acids (4). It is a 
good drug target for different cancers. It is over-expressed in different cancers including ovarian (5), prostate (6) and lung cancers (7). CXCR4 overexpression is correlated with poor prognosis in cancer therapy. Numerous clinical studies showed that patients with high CXCR4-expressing tumors had significantly decreased survival rate in lung cancer (8), acute myeloid leukemia (9) and renal cell carcinoma (10). High CXCR4 expression was correlated with poor response to sunitinib (a chemotherapy drug) for patients with metastatic renal cancer $(10,11)$. CXCR4 can bind to its ligand CXCL12 (also known as stromal cell-derived factor 1, SDF-1) (12). Studies with a neuroblastoma or prostate tumor mouse model showed that high CXCL12 expression in the tumor cells recruited CXCR4-positive monocytes and stimulated the formation of new tumor blood vessels $(13,14)$. Furthermore, tissues with high CXCL12 expression, such as lymph nodes, liver and lung, are the most common cancer metastatic sites, and cancer cells migrate to these tissues in a CXCL12-dependent manner (15). CXCR4/ CXCL12 axis is involved in tumor progression. The activation of CXCR4 by CXCL12 mediates tumor cell survival and proliferation and enhances primary tumor progression, angiogenesis and metastasis (16). Therefore, CXCR4/CXCL12 axis is a significant target for tumor therapy.

Targeted therapy becomes a major cancer treatment due to its specific anti-cancer effect and less side effect (17). CXCR4 antagonists are in different development stages. The smallmolecule CXCR4 antagonist Plerixafor (also named as AMD3100) was approved by FDA for hematopoietic stem cell mobilization as an injectable agent, and it can block CXCR4 activation to inhibit metastasis of multiple solid tumors $(16,18)$. Monoclonal antibodies (mAbs) are attractive medicines for cancer treatment (19). Ulocuplumab (BMS-936564) is a mAb against CXCR4, and is currently in phase Ib/II study to determine its safety and tolerability for patients with relapsed/refractory multiple myeloma (20). F50067, a humanized mAb targeting CXCR4, demonstrated preclinical anti-tumor activity in multiple myeloma, and phase I study was performed to assess the safety and efficacy of F50067 alone and in combination with lenalidomide and dexamethasone in relapsed or refractory multiple myeloma (21). However, $\mathrm{mAb}$ has the following major disadvantages: it is difficult in penetrating tumor tissues due to its large size $(150 \mathrm{kDa})$. It contains antigenicity because it is commonly isolated in mice, and the mouse $\mathrm{mAb}$ is recognized as a foreign antigen by human. It is expensive to be manufactured because it needs to be expressed in mammalian cells. Therefore, the low molecular weight antibody fragments, such as single-chain variable fragment $(\mathrm{scFv})$, are regarded as good alternatives for conventional mAbs. scFv has the following advantages compared with mAb (22): it can easily penetrate into the tumor tissue due to its small molecular weight. It contains no antigenicity if it is isolated from a human $s c F v$ library. It can be produced in bacteria, thereby greatly reducing the manufacturing cost $(23,24)$. scFv does not contain Fc domain of $\mathrm{mAb}$ so that it cannot mediate antibody dependent cell-mediated cytotoxicity (ADCC), complement-dependent cytotoxicity (CDC), and antibody-mediated opsonization. Lack of Fc can decrease its efficacy for cancer therapy, but scFv can be modified in different ways to increase its efficacy for therapeutic use as described below.
scFv antibody comprises a variable region of heavy chain and a variable region of light chain, and the two chains are connected by a short peptide linker (25). It can act as an antagonist to block tumor growth signaling, induce tumor cell apoptosis and suppress tumor growth (22). scFv antibody can be modified to become a bivalent antibody by combining two different scFvs targeting two different target proteins. It can also be an immune conjugate by fusing a tumor-targeting $\mathrm{scFv}$ with a toxin molecule (26). scFvs may become major therapeutics for targeted cancer therapy.

In this study, the CXCR4 extracellular loop 2 (ECL2) was selected as an antigen for screening a human $\mathrm{scFv}$ antibody library. Three human anti-CXCR4 scFvs were isolated from a human scFv library by yeast two-hybrid technology (27). They were expressed in E. coli, purified and refolded. The binding of these three anti-CXCR4 scFvs to CXCR4 was confirmed. They could inhibit cancer cell proliferation, migration and invasion and promote the cancer cell apoptosis in vitro. Two of these three scFvs were further tested for their anti-tumor effect in vivo, and they could inhibit the tumor growth in a prostate cancer xenograft mouse model. These anti-CXCR4 scFvs may become potential anti-cancer therapeutics for the treatment of different cancers.

\section{MATERIALS AND METHODS}

\section{Materials}

Anti-His antibody-HRP was purchased from Thermo Fisher (Waltham, MA, USA). Saccharomyces cerevisiae strain AH109, YPD medium and yeast selective culture medium were purchased from Clontech (Palo Alto, CA, USA). T4 DNA ligase and restriction enzymes were purchased from Takara Biomedicals (Kyoto, Japan). pGBKT7-CXCR4 was constructed and optimized by Genewiz (Suzhou, China). E. coli strains (DH5a, BL21) and Ni-MAC Cartridge were from Novagen. Primary antibodies against Bax, Bcl-2, cleaved caspase-8 (ccaspase-8), cleaved caspase-3 (c-caspase-3), cleaved-PARP-1 (c-PARP-1), HRP-conjugated secondary antibody, and Alexa Fluor 488-labeled secondary antibody were from Beyotime Biotechnology (Shanghai, China). Primary antibody against pro-caspase-9 was from ZFdows BIO (Nanjing, China). Primary antibody against p-p53 and secondary antibody mIgGK BP-HRP were from Santa Cruz Biotechnology (CA, USA). Primary antibody against $\beta$-actin was from ZSGB-BIO (Beijing, China).

\section{Assays for the Bait Plasmid Autonomous Activation}

To examine the bait plasmid autonomous activation, yeast competent cell AH109 was prepared and transformed with bait plasmid (pGBKT7-CXCR4). The transformed AH109 was plated on the following media: SD/-Trp, SD/-Trp/-His, or SD/-Trp/Ade. These plates were incubated at $30^{\circ} \mathrm{C}$ for $3-6$ days and observed whether the colonies could grow. 


\section{The Human scFv Library Screening}

The human scFv library was constructed by referring to the previous reports (28-30). Briefly, human PBMCs were isolated using Ficoll Paque Plus (Amersham Pharmacia Biotech, Piscataway, NJ, USA) according to the manufacturer's instructions. mRNA was extracted from PBMCs using the Dynabeads mRNA direct kit (Invitrogen) and was used to synthesize full-length cDNA with the SMART cDNA library construction kit (Clontech). The variable regions of human immunoglobulin (Ig) heavy-chains (VH) and light-chains (VL) were amplified by polymerase chain reactions (PCRs) using a set of primers as previously described $(28,29)$, and the VH and VL gene repertoires were linked by overlapping extension PCR. The $\mathrm{scFv}$ fragments were cloned into yeast vector to generate the human scFv library.

After yeast AH109 competent cells were transformed with the pGBKT7-CXCR4 plasmid, they were also transformed with the human scFv library. They were incubated on SD/-Trp/-Leu/His $+10 \mathrm{mM} 3-\mathrm{AT}$ plates. The colonies which grew on the plates were randomly picked and re-streaked on SD/-Trp/-Leu/-His/Ade $+10 \mathrm{mM} 3$-AT plates and incubated at $30^{\circ} \mathrm{C}$ for $4-6$ days to confirm the positive colonies. The candidate positive colonies were transferred to SD/-Trp/-Leu/-His/-Ade liquid medium and cultured at $30^{\circ} \mathrm{C}$ at $250 \mathrm{rpm}$. The plasmid DNA was isolated from each colony using the yeast plasmid isolation kit (Clontech). Each colony plasmid DNA was transformed into AH109 containing empty vector pGBKT7, bait vector pGBKT7CXCR4, or the vectors containing the control antigens. Each anti-CXCR4 scFv antibody clone was DNA-sequenced, and the DNA sequence from each clone was compared with each other to identify the same clones.

\section{Purification and Refolding of ScFv Antibody Proteins}

Each anti-CXCR4 scFv gene was cloned in pET-28a-sumo vector containing His tag. The plasmid DNA was transformed into BL21. Each colony was cultured in $4 \mathrm{ml} \mathrm{LB}$ including $50 \mu \mathrm{g} / \mathrm{ml}$ of Kanamycin. Then, bacteria were cultured in $400 \mathrm{ml} \mathrm{LB}$ including $50 \mu \mathrm{g} / \mathrm{ml}$ of Kanamycin until the optical density reached OD600 $0.6-0.8$. Bacteria were cultured with IPTG $(0.5 \mathrm{mM})$ for $6 \mathrm{~h}$ at $37^{\circ} \mathrm{C}, 30^{\circ} \mathrm{C}, 25^{\circ} \mathrm{C}$ or $18^{\circ} \mathrm{C}$. The total bacterium proteins were analyzed by $12 \%$ SDS-PAGE.

Following the IPTG induction, the bacteria were lysed by sonication. After the centrifugation at $13,000 \mathrm{~g}$ for $30 \mathrm{~min}$ at $4^{\circ} \mathrm{C}$, the bacteria were washed twice with the buffer containing $50 \mathrm{mM}$ Tris- $\mathrm{HCl}$ ( $\mathrm{pH} 8.0$ ), $150 \mathrm{mM} \mathrm{NaCl}$ and 2\% Triton X-100 for $2 \mathrm{~h}$ each time at room temperature. The inclusion bodies were solubilized in the buffer containing $50 \mathrm{mM}$ Tris- $\mathrm{HCl}(\mathrm{pH} \mathrm{8.0)}$, $8 \mathrm{M}$ urea, $0.5 \mathrm{M} \mathrm{NaCl}$ and $10 \mathrm{mM} \beta$-mercaptoethanol for $2.5 \mathrm{~h}$ at room temperature, and centrifuged at $18,000 \mathrm{~g}$ for $30 \mathrm{~min}$ at $4^{\circ} \mathrm{C}$ to remove insoluble materials. The supernatant was filtered through $0.22 \mu \mathrm{m}$ filter (Millipore, Billerica, MA, USA) to remove any remaining insoluble materials. The $\mathrm{scFv}$ proteins were purified by a Ni-MAC Cartridge (Novagen) under denaturing conditions ( $8 \mathrm{M}$ urea). The purified scFv proteins were analyzed by SDS-PAGE.
Refolding of the scFv proteins was carried out by the stepwise dialysis method, which included dialysis against the buffer (3 $\mathrm{mM} \mathrm{GSH}, 1 \mathrm{mM}$ GSSG and $150 \mathrm{mM} \mathrm{NaCl}$ ) containing urea at 8 , $4,2,1,0.5,0.25$, or $0 \mathrm{M}$. The refolded proteins were dialyzed against Tri-HCl ( $\mathrm{pH}$ 9.0) and centrifuged at 13,000 g for $30 \mathrm{~min}$ to remove the insoluble materials. The refolded $\mathrm{scFv}$ proteins were analyzed by SDS-PAGE under non-reducing conditions and the protein concentrations were determined by the Bradford method.

\section{Western Blot Analysis}

For Western blot analysis of anti-CXCR4 scFv protein expression, the total bacterial proteins were separated on a $12 \%$ SDS-PAGE and transferred to a PVDF membrane. After the membrane was blocked for $60 \mathrm{~min}$ at room temperature in the blocking buffer (PBS containing 0.5\% Tween-20 and 5\% nonfat dry milk powder), it was kept with anti-His $6 \mathrm{mAb}$ overnight at $4^{\circ} \mathrm{C}$. After washing, the membrane was kept with HRP-conjugated goat anti-mouse IgG $(1 / 10,000)$ for $60 \mathrm{~min}$ at room temperature. The bands were visualized with ECL Western blot detection system.

To detect the expression of the apoptosis-related proteins Bax, Bcl-2, p-p53, pro-caspase-9, c-caspase-8, and c-caspase-3, Western blot analysis was performed as described above. Cells were incubated for $48 \mathrm{~h}$ with the scFv proteins or negative control antibodies $(75 \mu \mathrm{g} / \mathrm{ml})$ or PBS as a control. The membranes were incubated with the primary antibodies and HRP-conjugated secondary antibodies. $\beta$-actin was used as an internal control. The images were analyzed with ImageJ software (NIH, Bethesda, MD).

\section{Binding of the Anti-CXCR4 scFvs to CXCR4 Protein Was Detected By ELISA}

A 96-well plate was incubated with the CXCR4 protein $(0.2 \mu \mathrm{g}$ each well) purchased commercially (Shanghai Bootech BioSci. and Technol., Shanghai, China). After washing with PBS, it was treated with BSA. Solution was removed, and it was treated for $1 \mathrm{~h}$ at $37^{\circ} \mathrm{C}$ with the purified anti-CXCR4 scFvs. After washing with PBS, it was treated for $1 \mathrm{~h}$ at room temperature with antiHis-HRP at 1:1,000 dilution. After it was washed, $100 \mu \mathrm{l}$ TMB was added. Then, $50 \mu \mathrm{l}$ of $1 \mathrm{M}$ sulfuric acid was added. The optical density was detected.

\section{Binding of the Anti-CXCR4 scFvs to Cells Was Detected by Flow Cytometry}

Cells $\left(1 \times 10^{6} / \mathrm{ml}\right)$ were incubated on ice for $1 \mathrm{~h}$ with the test reagents. After washing cells for three times, anti-CXCR4 scFvs, negative control antibodies or no antibody control were examined by PE-conjugated anti-His 6 antibody. Anti-CXCR4 antibody (positive control) or isotype control antibody were examined by PE-conjugated mouse IgG kappa binding protein. Cells were examined with FACS Calibur. FlowJo was used to examine the data.

\section{Cell Proliferation Assay}

Cancer cells (DU145, PC3, and MDA-MB-231, ATCC) were incubated overnight in culture medium containing 10\% FBS. 
Following the starvation, cells were washed and cultured for three days with serum-free medium containing CXCL12 (100 ng/ml, Sino Biological) and the anti-CXCR4 scFvs. They were cultured with MTT (Sigma) at $37^{\circ} \mathrm{C}$ for $4 \mathrm{~h}$. After removing culture medium, DMSO was included, and optical density was detected.

\section{Detection of Apoptosis by Flow Cytometry}

Cells were incubated overnight. After the starvation for $4 \mathrm{~h}$ in serum-free culture medium, CXCL12 (100 ng/ml) and the antiCXCR4 scFvs, the negative control antibodies $(50 \mu \mathrm{g} / \mathrm{ml})$ or PBS as a control were added to cells, and cells were cultured for two days at $37^{\circ} \mathrm{C}$. They were cultured for $15 \mathrm{~min}$ in dark with Annexin-V/FITC and PI (Sangon Biotech). Flow cytometer FACS Calibur was used to detect the apoptosis, and the results were examined with the FlowJo.

Expression of apoptosis-related proteins Bax, Bcl-2, ccaspase-3, and c-PARP-1 was detected by flow cytometry as described above. The three cancer cell lines were treated for $48 \mathrm{~h}$ with the anti-CXCR4 scFvs, the negative control antibodies (75 $\mu \mathrm{g} / \mathrm{ml}$ ), or PBS as a control. Cells were incubated for $1 \mathrm{~h}$ with primary antibodies and for $1 \mathrm{~h}$ with Alexa Fluor 488-labeled secondary antibody.

\section{Wound Healing Assay}

Cells (DU145, PC3, and MDA-MB-231) were incubated in a 12well plate in culture medium containing $10 \%$ FBS. After the starvation for $4 \mathrm{~h}$, cell monolayers were scratched. Cells were incubated in culture medium supplemented with $1 \%$ FBS, CXCL12 (100 ng/ml) and the anti-CXCR4 scFvs or negative control antibodies. Images were taken at 0 and $24 \mathrm{~h}$ after the cell wounds were made. The wound widths were determined by Image-Pro Plus 6.0. The migration percentages were determined: $\mathrm{Lm}=(\mathrm{L} 0-\mathrm{Lt}) / \mathrm{L} 0 \times 100 \%$. Lm is the migration percentage, $\mathrm{L} 0$ is wound width at $0 \mathrm{~h}$, and Lt is wound width at $24 \mathrm{~h}$.

\section{Transwell Assay}

For the detection of cell migration, cells in culture medium including 1\% FBS were placed to each transwell (BD Biosciences) that was put in a 24 -well plate. Each well was filled with culture medium including 20\% FBS. Cells were incubated for one day with CXCL12 (100 ng/ml) and the anti-CXCR4 scFvs or negative control antibodies. Cells in the upper chamber were gently scraped off. The cells that crossed over the membrane were treated with crystal violet, and images were photographed. Crystal violet of stained cells was solubilized in acetic acid. Optical density was detected. For the detection of cell invasion, matrigel was placed in transwells, and then, cells were added. The other steps are the same as described above.

\section{Xenograft Mouse Model}

The animal study protocols were approved by the Institutional Animal Care and Use Committee of Jinan University. Fourweek-old $\mathrm{BALB} / \mathrm{c}$ nude mice were from Beijing HuaFuKang Bioscience. Six-week-old mice were inoculated with DU145 cells subcutaneously into the right flank. After tumors were about $100 \mathrm{~mm}^{3}$, mice were randomized to the different groups.
The anti-CXCR4 scFvs, negative control antibody (Her2-13C1) (10 $\mathrm{mg} / \mathrm{kg}$ ) or DDP (2 $\mathrm{mg} / \mathrm{kg})$ were administrated by intravenous inoculation. The tumor volume (V) was determined: $\mathrm{V}=\left(\right.$ length $\times$ width $\left.^{2}\right) / 2$.

\section{Immunohistochemical Staining}

After euthanization of the mice on day 24 after the first inoculation, the tumors were excised. Paraffin blocks were prepared and sectioned. The tissue sections were incubated with HE, or antibodies against Ki67, CD31, and c-caspase-3. After washing, they were treated with goat anti-rat antibody conjugated with HRP. After washing, they were treated with $\mathrm{DAB}$ chromogen. The images were taken. Image-Pro Plus was used to analyze the images for IOD (integrated optical density).

\section{Statistics}

GraphPad Prism was used to make the images. One-way analysis of variance test (one-way ANOVA) was used for data analysis. The results represent mean \pm SD. $P<0.05$ indicates statistically significant.

\section{RESULTS}

\section{Identification of the Positive Anti-CXCR4 scFv Clones}

The bait plasmid pGBKT7-CXCR4 was transformed into yeast strain AH109 to detect the autonomous activation. Result showed that AH109 transformed with pGBKT7-CXCR4 could grow on SD/-Trp plate, but, not on SD/-Trp/-Ade and SD/-Trp/His plates (Figure 1A). This result proved that the bait plasmid did not activate Ade and His reporter genes. Furthermore, AH109 transformed with pGBKT7-CXCR4 grew at the same rate as AH109 transformed with the empty vector. Therefore, the bait plasmid was suitable for yeast two-hybrid screening.

Bait plasmid pGBKT7-CXCR4 was transformed into yeast AH109 competent cells, into which the human scFv antibody library was subsequently also transformed. A total of 241 candidate positive scFv clones grew on the SD/-Trp/-Leu/-His plates containing $10 \mathrm{mM} 3$-AT (Figure 1B). These clones were re-streaked in SD/-Trp/-Leu/-His/-Ade plates containing $10 \mathrm{mM}$ $3-\mathrm{AT}$, and 221 candidate positive scFv clones were obtained (Figure 1C). In order to eliminate the false positive clones, plasmid DNA of these clones was transformed into AH109 containing empty vector pGBKT7, which was cultured on SD/Trp/-Leu/-His/-Ade plates containing $10 \mathrm{mM}$ 3-AT. The clones which grew on the plates were false positive clones. A total of 85 candidate positive scFv clones that did not grow on the plates were obtained (Figure 1D). Plasmid DNA of these clones was transformed into AH109 containing bait plasmid pGBKT7CXCR4, and 14 candidate positive scFv clones grew on the $\mathrm{SD} /$-Trp/-Leu/-His/-Ade plates containing $10 \mathrm{mM}$ 3-AT (Figure 1E). Plasmid DNA of these clones was transformed into AH109 containing vectors with the unrelated antigens to determine the specificity of these clones. Only three positive scFv clones specifically bound to bait plasmid pGBKT7-CXCR4, not to the other unrelated antigens (Figure 1F). 

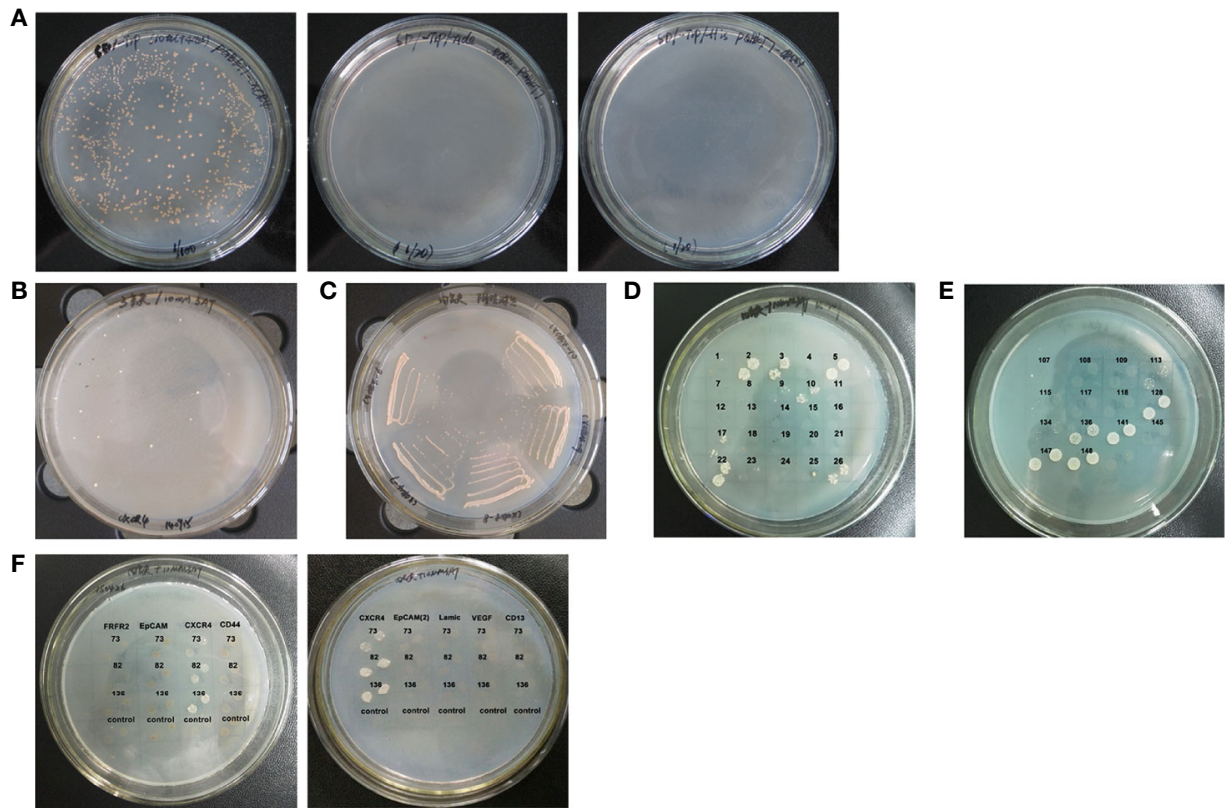

FIGURE 1 | Cloning anti-CXCR4 scFvs from human scFv antibody library. (A) Yeast strain AH109 competent cells were transformed with the bait plasmid pGBKT7CXCR4 and cultured on the different plates. The clones grew on SD/-Trp plate (Left), but not on SD/-Trp/-Ade plate (Middle) and SD/-Trp/-His plate (Right). These results showed that the bait plasmid alone did not activate the expression of the reporter genes. (B) A total of 241 candidate positive scFv clones were obtained from screening the scFv library. The image shows some representative clones of the 241 candidate positive clones which grew on SD/-Trp/-Leu/-His plates containing $10 \mathrm{mM}$ 3-AT. (C) The image shows some representative clones of the 241 candidate positive ScFv clones which were re-streaked on SD/-Trp/-Leu/-His/Ade plates containing $10 \mathrm{mM} 3-\mathrm{AT}$, so that the clones which grew on the plate were the candidate positive scFv clones, and the false positive clones did not grow. A total of 221 candidate positive scFv clones were identified. (D) The image shows some representative clones of the 221 candidate positive scFv clones from which the plasmid DNA was isolated and transformed into AH109 containing empty vector pGBKT7. The clones which grew on SD/-Trp/-Leu/-His/-Ade plates containing $10 \mathrm{mM}$ 3-AT were false positive clones, and the candidate positive clones did not grow. A total of 85 candidate positive scFv clones were obtained. (E) The image shows some representative clones of the 85 candidate positive scFv clones from which the plasmid DNA was isolated and transformed into AH109 containing bait plasmid pGBKT7-CXCR4, which were cultured on the SD/-Trp/-Leu/-His/-Ade plates containing $10 \mathrm{mM}$ 3-AT. A total of 14 candidate positive scFv clones were obtained. (F) The images show some representative clones of the 14 positive clones from which the plasmid DNA was isolated and transformed into AH109 containing bait plasmid pGBKT7-CXCR4 or the unrelated antigens as negative controls. Three positive clones contained scFvs which could interact with CXCR4 but, not with the unrelated antigens.

These three scFv clones were DNA-sequenced, and analyzed by DNAMAN software. Three different anti-CXCR4 scFvs were identified and named aCX73, aCX82, and aCX136. Their DNA sequences were submitted to European Nucleotide Archive under accession number LR743525, LR743526 and LR743527, respectively. These three scFv DNA sequences were translated to amino acid sequences, which were compared. Amino acid sequence alignment of the three scFvs demonstrated that the CDR regions of their antibody heavy chains and light chains were different from each other.

\section{Expression, Purification, and Refolding of scFv Proteins From Inclusion Bodies}

The three scFvs were cloned to pET-28a-sumo expression vector. The recombinant plasmids were transformed into $E$. coli, and induced by $0.5 \mathrm{mM}$ IPTG at $37^{\circ} \mathrm{C}, 30^{\circ} \mathrm{C}, 25^{\circ} \mathrm{C}$, or $18^{\circ} \mathrm{C}$. The results showed that anti-CXCR4 scFv fusion proteins were overexpressed as inclusion bodies (Figure 2A).

Inclusion bodies of scFvs were obtained by cells sonication, centrifugation and solubilization in $8 \mathrm{M}$ urea. His-tagged scFvs in inclusion bodies were purified under denatured condition using nickel-chelating His-trap column. Each purified scFv showed a single band (Figure 2B), and these denatured scFvs were used for further refolding experiments.

In order to optimize the refolding conditions, an oxidoshuffling system was used by adding $1 \mathrm{mM}$ GSSG and $3 \mathrm{mM}$ GSH to the refolding buffer at different urea concentrations. The purity of the refolded scFvs was estimated by $12 \%$ SDS-PAGE. The predicted molecular mass of aCX73, aCX82 and aCX136 were $43.2 \mathrm{kDa}, 42 \mathrm{kDa}$, and $40 \mathrm{kDa}$, respectively, and were confirmed by Western blot analysis (Figure 2C).

\section{The Anti-CXCR4 scFvs Can Bind to CXCR4 Protein and Cancer Cells}

ELISA was performed to detect the binding of the three antiCXCR4 scFvs to CXCR4 protein. The data showed that the three scFvs could bind to CXCR4 (Figure 2D).

Flow cytometry analysis was performed to check whether the three anti-CXCR4 scFvs could bind to cancer cells. The three scFvs and the anti-CXCR4 antibody as the positive control could bind to the three cancer cell lines (DU145, PC3, and MDA-MB231), and have no or low binding to $293 \mathrm{~T}$ and $3 \mathrm{~T} 3$ as control 


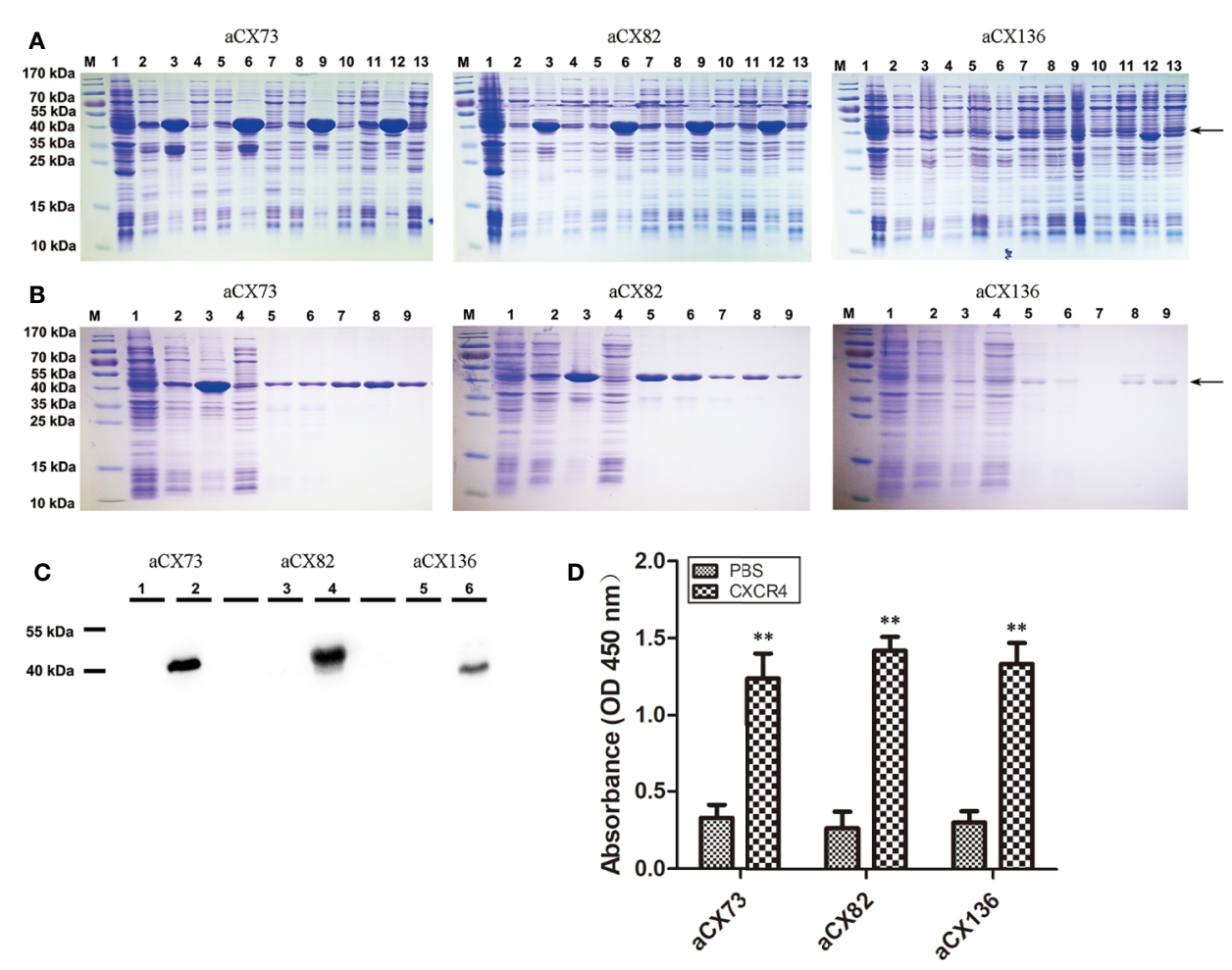

FIGURE 2 | Purification and analysis of the three anti-CXCR4 scFvs. (A) Detection of the expression of three anti-CXCR4 scFvs (aCX73, aCX82 and aCX136) by SDS-PAGE. M, marker; 1, total proteins of un-induced bacteria; 2-4, 5-7, 8-10, and 11-13, proteins of bacteria induced for $6 \mathrm{~h}$ with $0.5 \mathrm{mM} I P T G$ at $37^{\circ} \mathrm{C}, 30^{\circ} \mathrm{C}$, $25^{\circ} \mathrm{C}$, and $18^{\circ} \mathrm{C}$, respectively; $2,5,8$ and 11 , total proteins of induced bacteria; $3,6,9$, and 12 , insoluble portion of sonicated induced bacterium lysate; $4,7,10$, and 13, soluble supernatant of sonicated induced bacterium lysate. (B) scFv purification and refolding. M: marker; 1, total proteins of un-induced bacteria; 2-4, proteins of bacteria induced for $6 \mathrm{~h}$ with $0.5 \mathrm{mM} \mathrm{IPTG}$ at $30^{\circ} \mathrm{C} ; 2$, total proteins of induced bacteria; 3 , insoluble portion of sonicated induced bacterium lysate; 4 , soluble supernatant of sonicated induced bacterium lysate; 5 , solubilized inclusion bodies; 6, flow-through portion; 7, eluted portion with 0 mM imidazole; 8 , eluted portion with $250 \mathrm{mM}$ imidazole; 9, refolded scFvs. (C) The expression of the scFvs was confirmed by Western blotting with a mouse anti-His antibody. 1, 3, and 5, total proteins of un-induced bacteria; 2, 4, and 6, total proteins of induced bacteria. (D) ELISA was performed to detect the binding of the three purified anti-CXCR4 scFvs to the CXCR4 protein purchased. The results represent mean \pm S.D $(n=5) .{ }^{* *} P<0.01$.

cells. Two negative control antibodies (Her2-13C1 and aVE201) showed no or low binding to these cells (Figure 3). These two negative control antibodies were cloned previously in our group in a separate study (previously unpublished data) and could not bind to CXCR4.

For DU145 cells, percentages of aCX73, aCX82 and aCX136 positive cells were $74.5 \%$ (median fluorescence intensities (MFI) 30.4), 67.5\% (MFI 30.5) and 69.3\% (MFI 29.4) respectively. Conversely, only $2.76 \%$ (MFI 25.4 ) and $7.4 \%$ cells (MFI 23.6) were stained positive for Her2-13C1 and aVE201 (controls). For PC3 cells, percentages of aCX73, aCX82, and aCX136 positive cells were 69.8\% (MFI 35.8), 58.1\% (MFI 34.4), and $74.3 \%$ (MFI 36.7), respectively. Conversely, only 3.29\% (MFI 30.2 ) and $8.86 \%$ cells (MFI 29.3) were stained positive for Her2$13 \mathrm{C} 1$ and aVE201 (controls). For MDA-MB-231 cells, percentages of aCX73, aCX82, and aCX136 positive cells were 62.3\% (MFI 35.1), 62.8\% (MFI 34.9), and 56.3\% (MFI 33.7), respectively. Conversely, only $6.26 \%$ (MFI 28.5 ) and $7.59 \%$ cells (MFI 27.8) were stained positive for Her2-13C1 and aVE201 (controls). For the control cells (293T and 3T3), similar percentages and MFIs were detected for the three scFvs compared to the control antibodies (Figure 3).

\section{The Anti-CXCR4 scFvs Decrease Cancer Cell Proliferation}

Cell proliferation assay was performed to examine the effect of the three scFvs on the cancer cell proliferation. Data showed that the three scFvs decreased the proliferation of the three cancer cell lines (Figures 4A-C). Two negative control antibodies (Her213C1 and aVE201) did not decrease the cell proliferation. Percentages of growth inhibition were determined when cells were treated with the scFvs $(100 \mu \mathrm{g} / \mathrm{ml})$ compared to no $s c F v$ treatment controls. For DU145 cells, percentages of growth inhibition were $40.59 \%$ (aCX73), 33.90\% (aCX82), and 30.00\% (aCX136). For PC3 cells, percentages of growth inhibition were $31.82 \%$ (aCX73), 37.22\% (aCX82), and 34.64\% (aCX136). For MDA-MB-231 cells, percentages of growth inhibition were $24.62 \%$ (aCX73), 39.79\% (aCX82), and 40.82\% (aCX136) (Figures 4A-C). These results suggested that the three scFvs could inhibit the proliferation of these three cancer cell lines. 

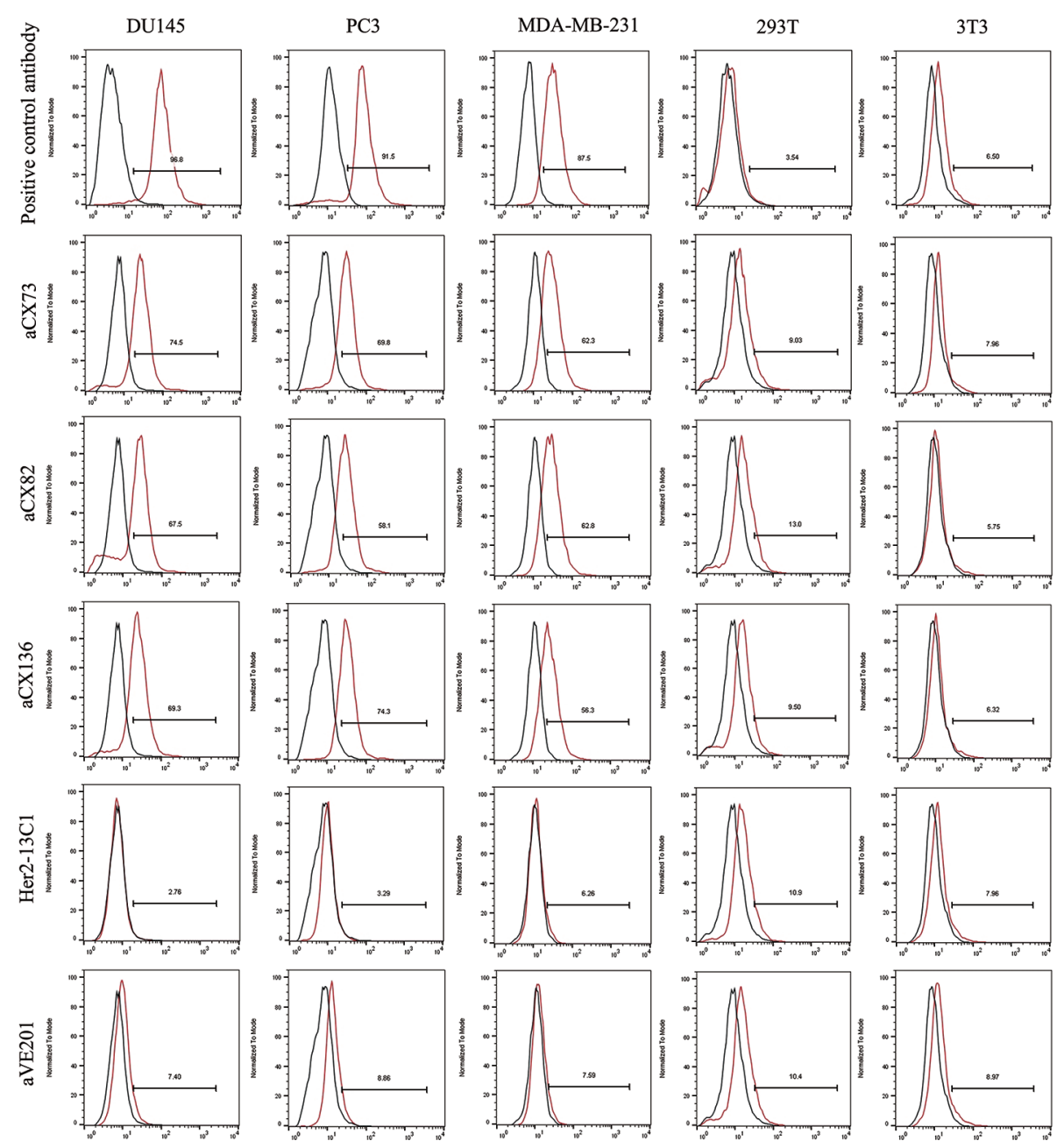

FIGURE 3 | The binding of the three anti-CXCR4 scFvs to cancer cells (DU145, PC3 and MDA-MB-231) was tested by flow cytometry. 293T and 3T3 cells were tested as controls. Binding of an isotype control antibody or no antibody control was shown as black curves. Binding of the three anti-CXCR4 scFvs, anti-CXCR4 positive control antibody or the negative control antibodies (Her2-13C1 and aVE201) was shown as red curves.

\section{Induction of Cancer Cell Apoptosis by scFvs Was Detected by Flow Cytometry}

The percentages of apoptotic cells were analyzed by flow cytometry with Annexin V-FITC and PI staining after DU145, PC3, and MDA-MB-231 cells were treated with different antibodies. The three scFvs induced apoptosis in DU145, PC3, and MDA-MB-231 compared with the PBS control (Figures 4D-I). In contrast, the two negative control antibodies (Her213C1 and aVE201) did not increase apoptosis in these cells.

Expression of the apoptosis-related proteins was also examined by flow cytometry. Expression of Bax (Figures 5A-C), c-caspase-3 (Figures 6A-C), and c-PARP-1 (Figures 6D-F) was up-regulated, and Bcl-2 expression (Figures 5D-F) was down-regulated after DU145, PC3 and MDA-MB-231 cells were treated with the three anti-CXCR4 scFvs compared to PBS control and two negative control antibodies (Her2-13C1 and aVE201). These results suggest that the three anti-CXCR4 scFvs can induce cell apoptosis in these three cancer cell lines.

\section{Induction of Cancer Cell Apoptosis by scFvs Was Detected by Western Blot Analysis}

To further study effect of the anti-CXCR4 scFvs on cell apoptosis, the expression of the apoptosis-related proteins was analyzed by Western blot analysis. Results showed that anti-CXCR4 scFvs induced the expression of the pro-apoptotic proteins Bax, p-p53, c-caspase-8, and c-caspase- 3 and decreased the expression of Bcl- 2 and pro-caspase- 9 in all three cancer cell lines compared to the PBS control (Figure 7). Anti-CXCR4 scFvs increased the Bax/Bcl-2 ratio in all three cancer cell lines. In DU145 cells, Bax/Bcl-2 ratio increased ranging from 7.17 to 11.23 compared to the PBS control (1.0). In PC3 cells, Bax/ $\mathrm{Bcl}-2$ ratio increased ranging from 12.69 to 20.72 compared to the PBS control (1.0). In MDA-MB-231 cells, Bax/Bcl-2 ratio increased ranging from 16.93 to 21.92 compared to the PBS control (1.0). The two negative control antibodies (Her2-13C1 and aVE201) did not affect the expression of these proteins compared to the PBS control. These results confirmed that the three anti-CXCR4 scFvs could induce cell apoptosis in these three cancer cell lines. 

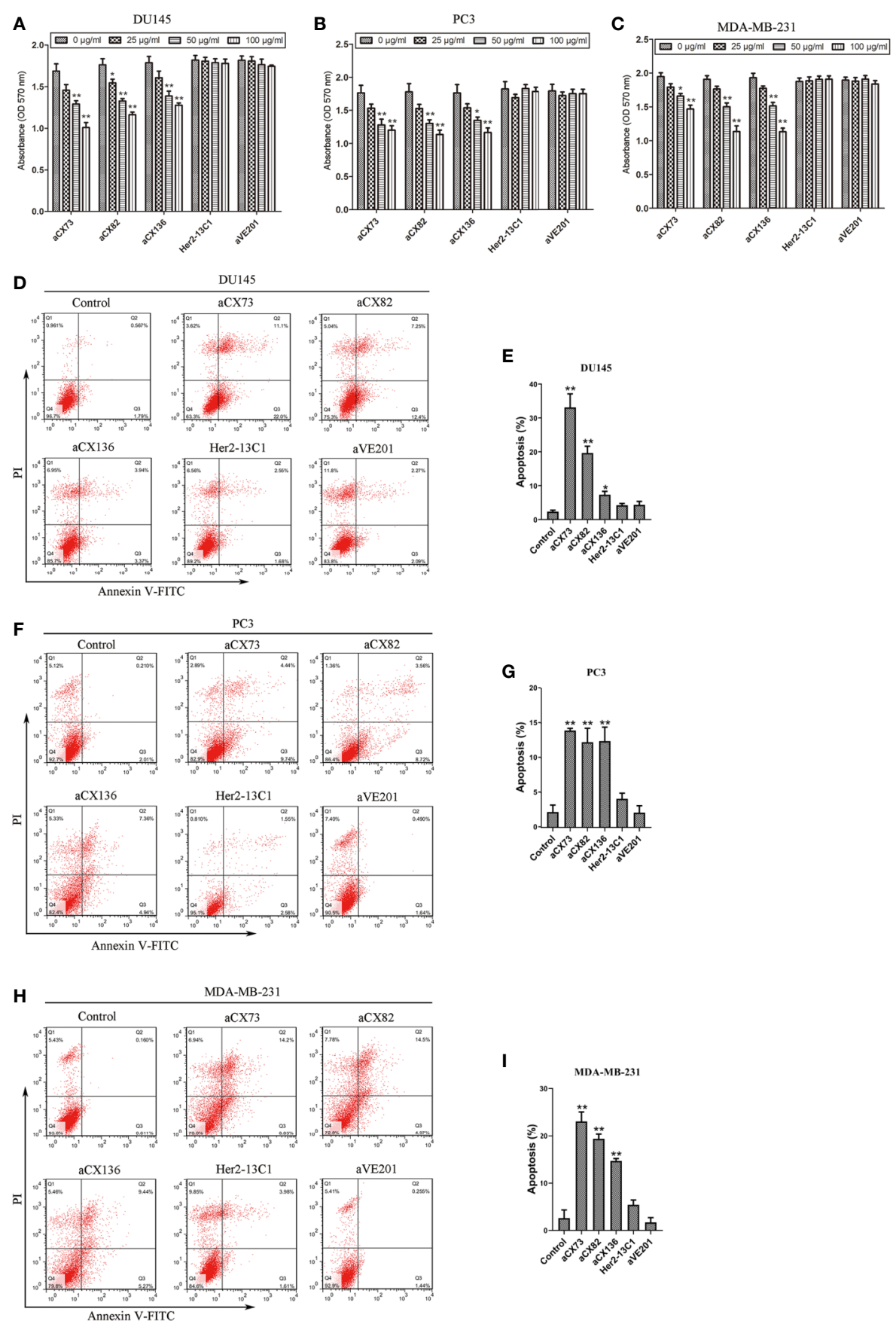

FIGURE 4 | Anti-CXCR4 scFvs can decrease cell multiplication and increase apoptosis. Cell multiplication was examined to detect the inhibitory effect of three antiCXCR4 scFvs (aCX73, aCX82 and aCX136) on the multiplication of DU145 (A), PC3 (B), and MDA-MB-231 (C). Cells were incubated for three days with CXCL12 $(100 \mathrm{ng} / \mathrm{ml})$ and the three anti-CXCR4 scFvs or negative control antibodies (Her2-13C1 and aVE201). Detection of apoptosis was carried out for DU145 (D, E), PC3 $(\mathbf{F}, \mathbf{G})$ and MDA-MB-231 (H, I). Cells were cultured for two days with the CXCL12 (100 ng/ml) and three anti-CXCR4 scFvs or negative control antibodies (Her2$13 \mathrm{C} 1$ and aVE201) $(50 \mu \mathrm{g} / \mathrm{mll})$. Apoptosis was detected by Annexin V-FITC and PI. The results represent mean \pm S.D $(n=5) .{ }^{*} P<0.05$ and ${ }^{* *} P<0.01$.

\section{scFvs Inhibit the Migration and Invasion of Cancer Cells}

Wound healing assay was performed to examine effect of the three scFvs on the migration of cancer cells. The three scFvs inhibited DU145, PC3, and MDA-MB-231 cell migration in a dose-dependent manner by wound healing assay (Figure 8). In contrast, the two negative control antibodies (Her2-13C1 and aVE201) had no effect on the migration of these cells. Transwell assay was also performed to examine effect of the three scFvs on the migration of cancer cells. The similar results were seen in 


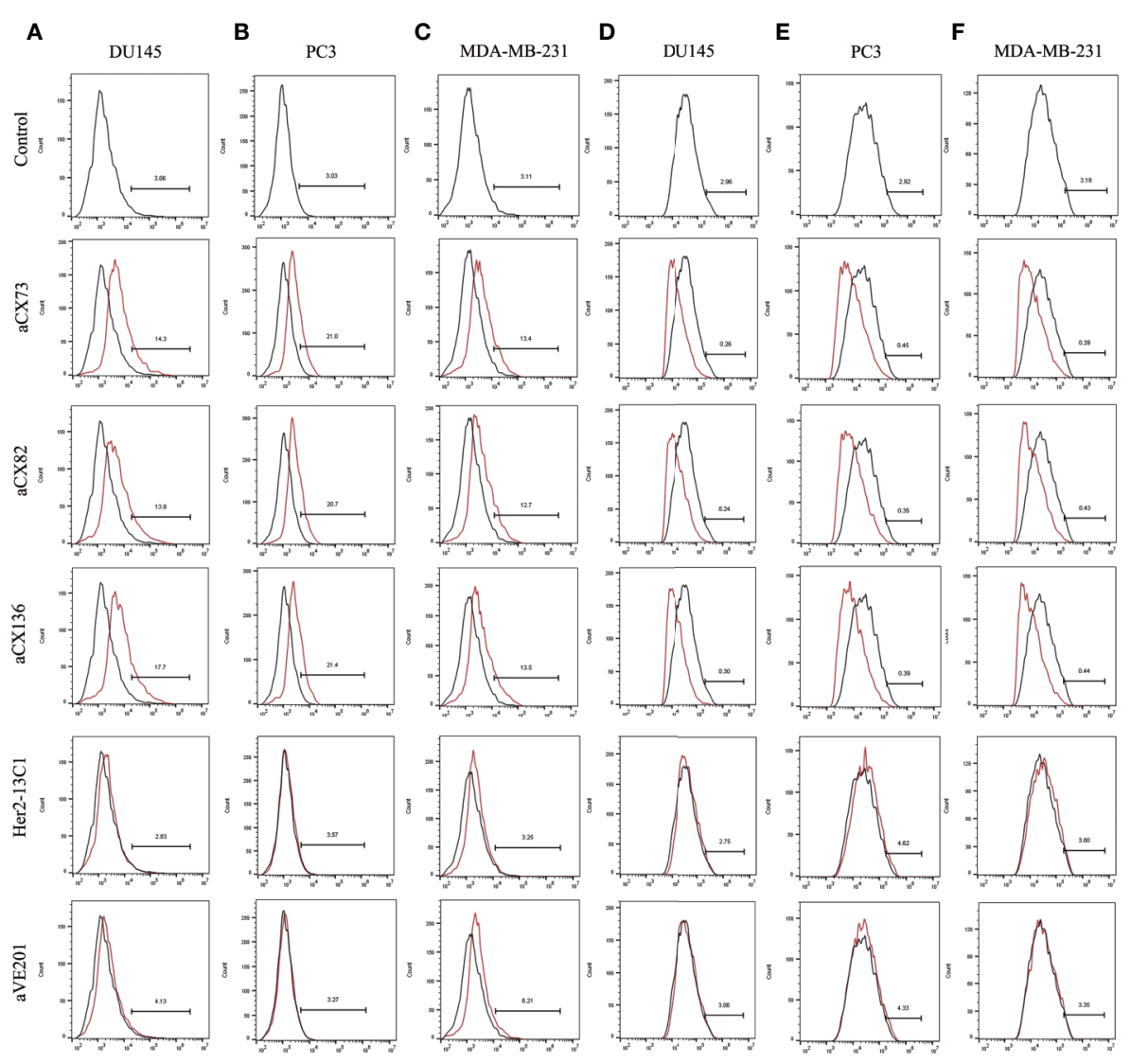

FIGURE 5 | Expression of the apoptosis-related proteins Bax and Bcl-2 was detected by flow cytometry. Bax expression was examined after DU145 (A), PC3 (B), and MDA-MB-231 (C) were treated for $48 \mathrm{~h}$ with the three anti-CXCR4 scFvs (aCX73, aCX82, and aCX136). Bcl-2 expression was also tested in DU145 (D), PC3 (E), and MDA-MB-231 (F). The PBS control and the two negative control antibodies (Her2-13C1 and aVE201) were also included.

transwell assay (Figures 9A-F). These results suggested that the three scFvs could decrease the migration of these cancer cells.

Effect of the three scFvs on the invasion of cancer cells was also tested by transwell invasion assay with the matrigel-coated transwells. The three scFvs inhibited DU145 invasion (Figures 9G, H). In contrast, the two negative control antibodies (Her2$13 \mathrm{C} 1$ and aVE201) did not affect the DU145 invasion. The same results were seen for PC3 (Figures 9I, J) and MDA-MB-231 (Figures 9K, L). These results suggested that the three scFvs could inhibit the invasion of these cancer cells.

\section{scFvs Decrease Tumor Growth in a Xenograft Model}

Animal study was performed to examine the effect of the scFvs on the inhibition of tumor growth in DU145 xenograft model. Mice were administrated with anti-CXCR4 scFvs (aCX73 and aCX82, $10 \mathrm{mg} /$ $\mathrm{kg}$ ), the negative control antibody (Her2-13C1, $10 \mathrm{mg} / \mathrm{kg}$ ) and DDP $(2 \mathrm{mg} / \mathrm{kg}$ ) as a positive control when the tumor volumes were about $100 \mathrm{~mm}^{3}$. On day 21 following the first injection of the test reagents, aCX73 (average tumor volume $342.1 \mathrm{~mm}^{3}, P<0.05$ ) and aCX82 (average $336.1 \mathrm{~mm}^{3}, P<0.05$ ) achieved a statistically significant reduction of tumor volumes compared to the negative control antibody Her2-13C1 (average $451.6 \mathrm{~mm}^{3}$ ). On day 24 following the first injection of the test reagents, aCX73 (average $390.1 \mathrm{~mm}^{3}, P<$ 0.05 ) and aCX82 (average $375.3 \mathrm{~mm}^{3}, P<0.05$ ) also showed a statistically significant reduction of tumor volumes compared to the negative control antibody Her2-13C1 (average $554.4 \mathrm{~mm}^{3}$ ) (Figures 10A, B). On day 24 following the first injection of the test reagents, all the mice were sacrificed and examined by the naked eye, and no clear gross anatomical change in organs including livers, kidneys, hearts, lungs and spleens and the other parts of bodies was observed from the mice treated with the three scFvs and the other test reagents, and no behavioral abnormalities or any color change in any parts of bodies were observed. This observation suggests that these scFvs may not induce obvious adverse side or toxic effects in mice and needs to be confirmed by blood tests on the mice analyzing the organ parameters and microscopic examination of the organs. The mice treated with these scFvs did not show the adverse side or toxic effects, such as diarrhea, fatigue and low food and water consumption.

On day 24, the tumor weight was also significantly lower in mice treated with the scFvs compared to the negative control antibody (Figure 10C). DDP as a positive control also showed a statistically significant tumor weight reduction compared to the negative control antibody. Each of Her2-13C1, aCX73 and DDP groups included five mice. The aCX82 group included four mice because only four mice containing about $100 \mathrm{~mm}^{3}$ tumor 


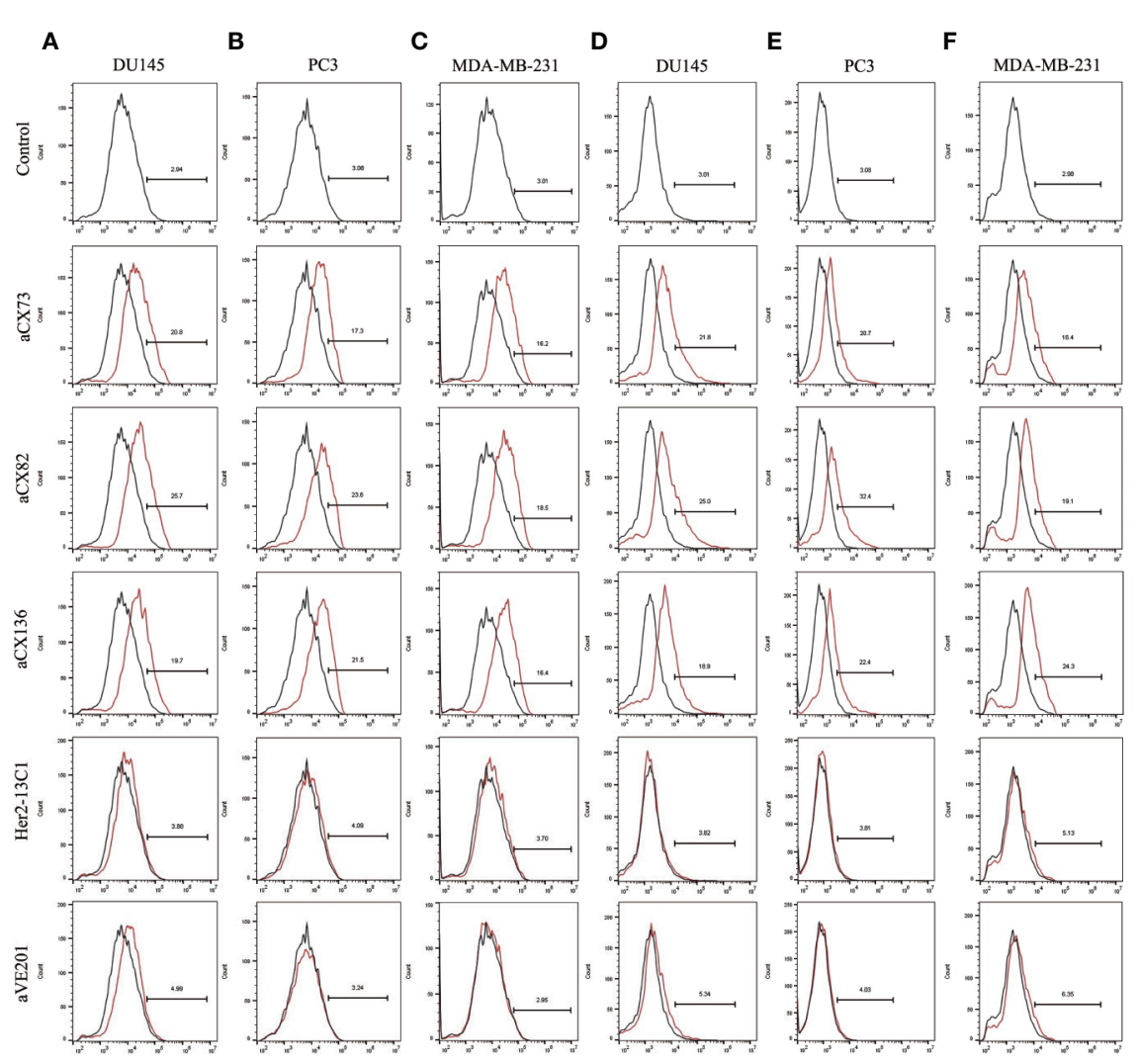

FIGURE 6 | Expression of the apoptosis-related proteins c-caspase-3 and c-PARP-1 was also detected by flow cytometry. C-caspase-3 expression was examined after DU145 (A), PC3 (B), and MDA-MB-231 (C) were treated for $48 \mathrm{~h}$ with the three anti-CXCR4 scFvs (aCX73, aCX82 and aCX136). C-PARP-1 expression was also tested in DU145 (D), PC3 (E), and MDA-MB-231 (F). The PBS control and the two negative control antibodies (Her2-13C1 and aVE201) were also included.

volumes were available for the first injection of this scFv. On day 24 following the first injection of the test reagents, all mice survived, and there was no difference in median survival time of mice among all the groups (Figure 10D). There was no difference in the risk of developing tumors in mice (hazard ratio) among all the groups (Table $\mathbf{1}$ ).

The tumor sections were stained with $\mathrm{HE}$ or antibodies against Ki67, CD31, and c-caspase-3, and the integral optical density (IOD) was calculated. Immunohistochemistry analysis of tumors showed a significantly decreased Ki67 and CD31 expression and a significantly increased c-caspase-3 expression in mice treated with the scFvs compared to the negative control antibody Her2-13C1 (Figures 10E, F), suggesting that the two scFvs significantly decreased cancer cell proliferation and tumor angiogenesis and increased cell apoptosis. These results suggested that the two anti-CXCR4 scFvs (aCX73 and aCX82) could inhibit the tumor growth in DU145 xenograft model.

\section{DISCUSSION}

CXCR4 is over-expressed in different cancer cells and is considered as a prognostic marker of various cancers including breast cancer (31), ovarian cancer (32), leukemia (33), prostate cancer (34), and colorectal cancer (35). Moreover, CXCL12/CXCR4 axis plays an important role in tumor growth and metastasis. Therefore, cancer treatment by targeting CXCR4 signaling pathways should be beneficial (15). Some cancer therapeutics was developed to target CXCR4/CXCL12 signaling pathways. AMD3100 is a small molecule CXCR4 antagonist and can inhibit CXCL12/CXCR4 signaling pathways. Studies showed that AMD3100 inhibited metastasis in animal models for ovarian and colorectal cancers, melanoma, and oral squamous cell carcinoma (36-41). mAbs, such as BMS-936564/MDX-1338 and LY2624587, could also suppress CXCR4/CXCL12 signaling pathways and inhibit tumor growth and metastasis in different animal models both in vitro and in vivo $(42,43)$.

Chemokine receptors including CXCR4 represent a sub-class of $\mathrm{G}$ protein-coupled receptors (GPCRs) containing seven transmembrane segments. Similar to other GPCRs, CXCR4 has an extracellular $\mathrm{N}$-terminus, seven transmembrane alpha helices connected by three extracellular loops (ECL) and three intracellular loops (ICL) and a C-terminus that is located in the cytoplasm. In addition to the disulfide bond between CXCR4 helix VII (Cys 274) and the N-terminal region (Cys 28), the 

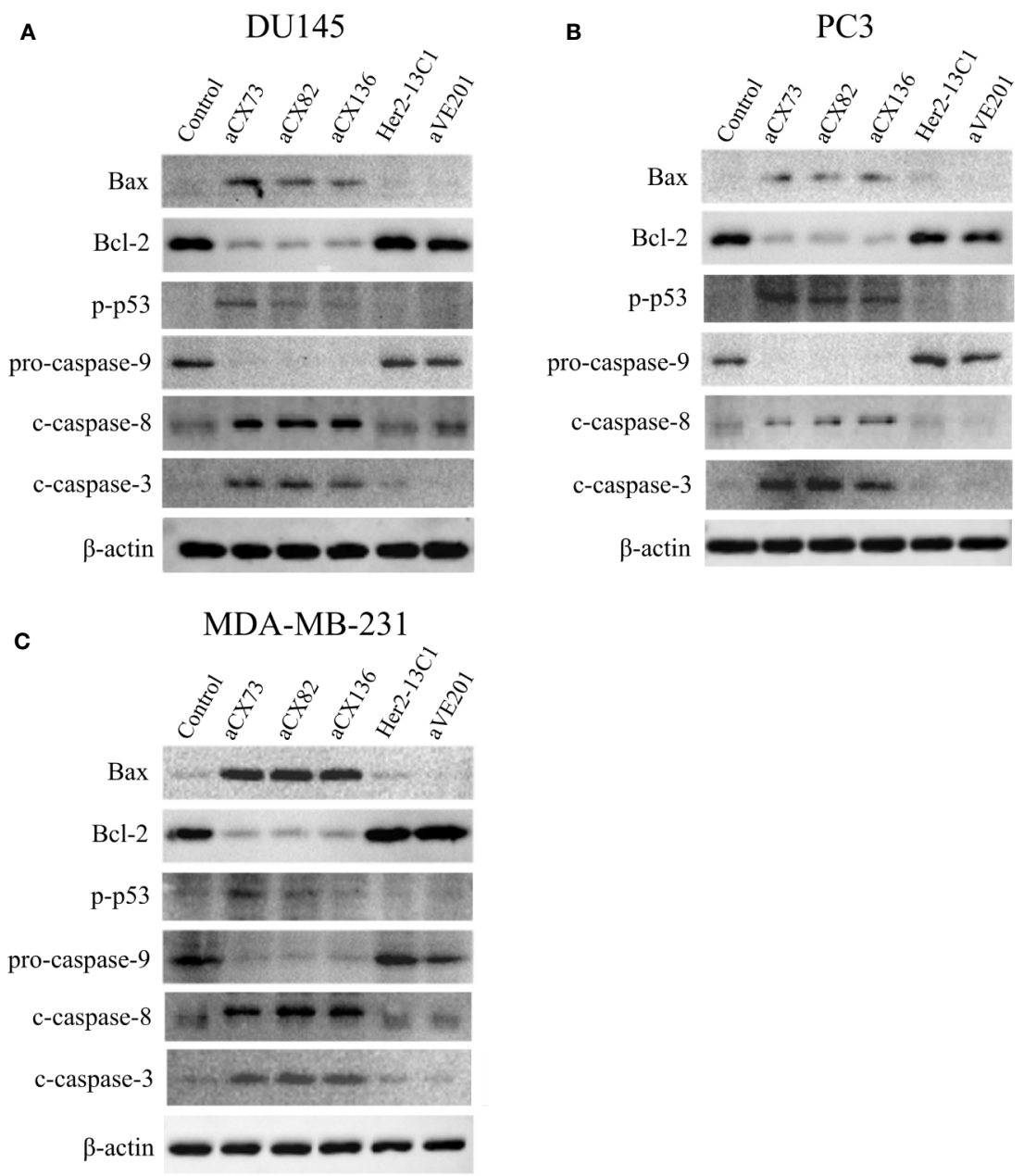

FIGURE 7 | Expression of the apoptosis-related proteins was examined by Western blot analysis. Cells were treated for $48 \mathrm{~h}$ with anti-CXCR4 scFvs (aCX73, aCX82, and aCX136), negative control antibodies (Her2-13C1 and aVE201), or PBS as a control. Effect of the antibodies on the expression of the apoptosis-related proteins was tested in DU145 (A), PC3 (B), and MDA-MB-231 (C). $\beta$-actin was used as an internal control. Western blots were analyzed using ImageJ software.

disulfide bond between CXCR4 ECL2 (Cys 186) and the extracellular end of alpha helix III (Cys 109) is essential for its ligand CXCL12 binding to CXCR4 by shaping the entrance to the ligand-binding pocket, and is highly conserved among the chemokine receptors $(44,45)$. Studies also showed that only the peptides derived from ECL2 were able to specifically bind to CXCL12 and inhibit its interactions with CXCR4 thereby preventing receptor activation (46). So, ECL2 is most likely to be the major determinant of the CXCR4 Chemokine Recognition Site 2 (CRS2) (46). In this study, the CXCR4 ECL2 was selected as an antigen for screening the human scFv antibody library. It may contribute to the anti-tumor effects of the anti-CXCR4 scFvs cloned in this study.

Human scFv antibody has the following advantages compared to the conventional mAb. It can easily penetrate into tumor tissue due to its small size and contains no antigenicity. It can greatly reduce the cost to be manufactured because it can be produced in E. coli. In addition, $s c F v$ can be modified to further increase its binding to antigen and its efficacy for cancer therapy (47). After two anti-CD123 scFvs were linked to form a bivalent $\mathrm{scFv}$ (biscFv), the overall efficacy of the anti$\mathrm{CD} 123$ biscFv in binding to CD123 and inhibiting the binding of CD123 to its ligand in TF-1 cells was significantly increased (48). An anti-EGFR scFv was fused to the plant toxin gelonin (rGel) to get a targeted toxin, which could selectively bind EGFRoverexpressing cells with high affinity and significantly suppressed the tumor growth of human NSCLC (49). Some anti-tumor small molecular drugs have no tumor specificity and high toxicity to normal tissues (50). To overcome this problem, a study showed that nanoparticle surfaces were covered with antiCD44v6 scFvs, and arsenite ion (As) as the anti-cancer drug was encapsulated inside the nanoparticles, thus providing a safe and targeted carrier for drug delivery. When the modified nanoparticles entered tumor cells by endocytosis, they were rapidly degraded, and arsenite ion was released into cytoplasm and induced cell apoptosis $(51,52)$. Therefore, $\mathrm{scFv}$ can be 

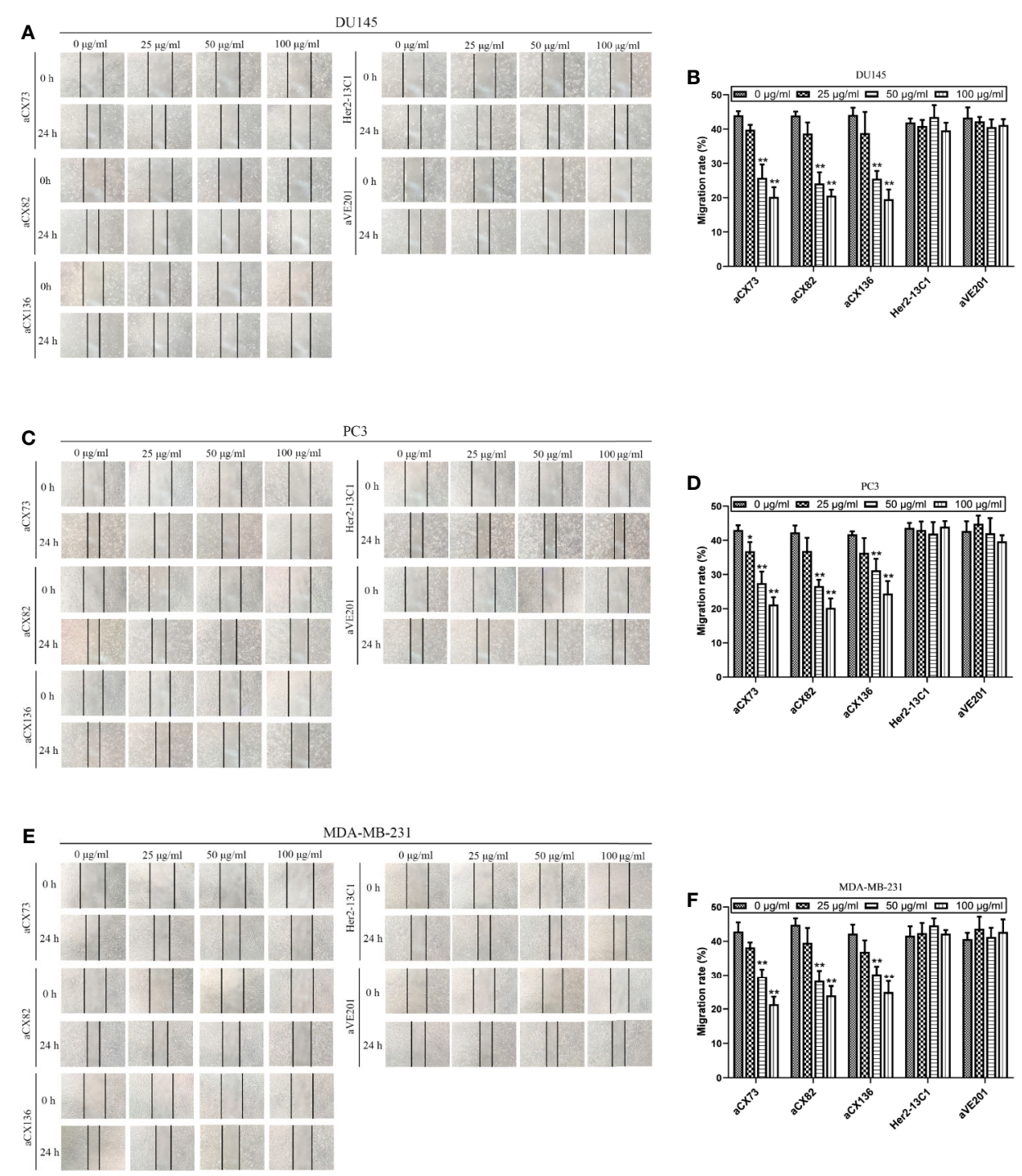

FIGURE 8 | Anti-CXCR4 scFvs can decrease cell migration detected by wound healing assay. Cells were cultured with CXCL12 (100 ng/ml) and the three antiCXCR4 scFvs (aCX73, aCX82, and aCX136) or negative control antibodies (Her2-13C1 and aVE201). Images were taken at 0 and $24 \mathrm{~h}$ after the cell wounds were made. The wound widths were determined. (A, B) DU145; (C, D) PC3; (E, F) MDA-MB-231. The results represent mean \pm S.D $(n=5) .{ }^{*} P<0.05$ and ${ }^{* *} P<0.01$.

modified to increase its binding to its antigen and enhance its efficacy for cancer therapy.

In this study, three anti-CXCR4 scFvs were isolated by the yeast two-hybrid system, which is based on the GAL4 protein properties of saccharomyces cerevisiae (27). Yeast two-hybrid system offers many advantages, such as high sensitivity, convenience, and cost-saving. However, it has a problem with getting false-positive clones. To solve this problem, two reporter genes (His and Ade) were used to provide strong nutrition screening and eliminate a large number of false-positive clones. $\mathrm{Trp}^{+}$bait plasmid and the $\mathrm{Leu}^{+} \mathrm{scFv}$ library plasmid were used to increase the number of positive clones. In addition, 3-AT can inhibit the background His expression and was added to SD/-
Trp/-Leu/-His/-Ade plates to effectively eliminate false positive clones (53). The empty plasmid pGBKT7 containing no additional protein and pGBKT7-X (X as an unrelated protein) were also included as controls in the library screening process. In this study, three anti-CXCR4 scFvs were obtained from the human $\mathrm{scFv}$ library by yeast two-hybrid system, and they showed anti-tumor effect in vitro and in vivo.

This study showed that anti-CXCR4 scFvs induced the expression of the pro-apoptotic proteins Bax, p-p53, c-caspase8, c-caspase-3, and c-PARP-1 and decreased the expression of Bcl-2 and pro-caspase-9 in all three cancer cell lines compared to the two negative control antibodies (Figures 5-7). BAX is a member of the Bcl-2 gene family and promotes apoptosis by 

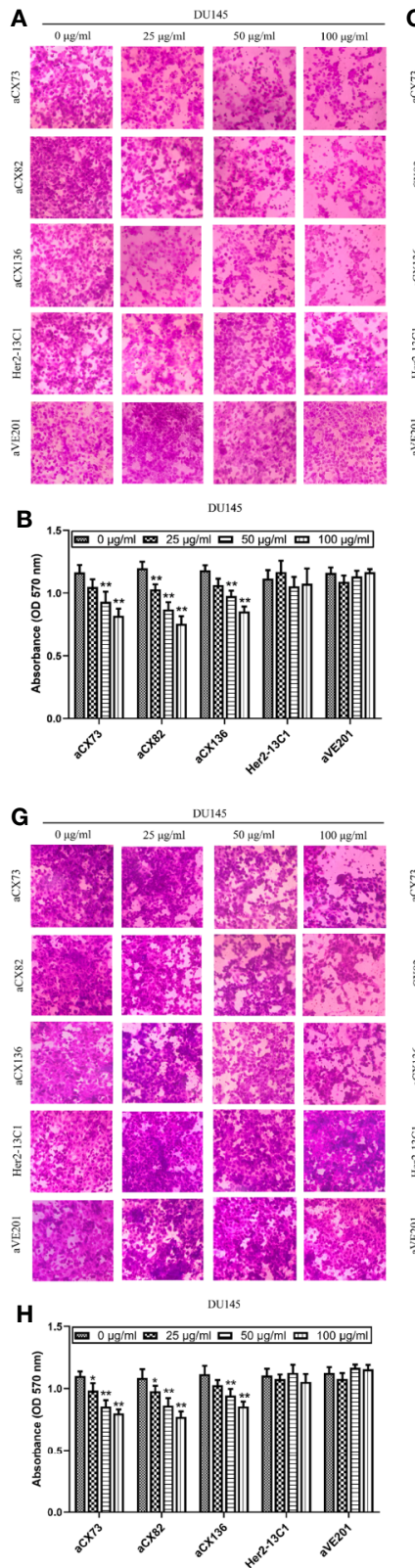
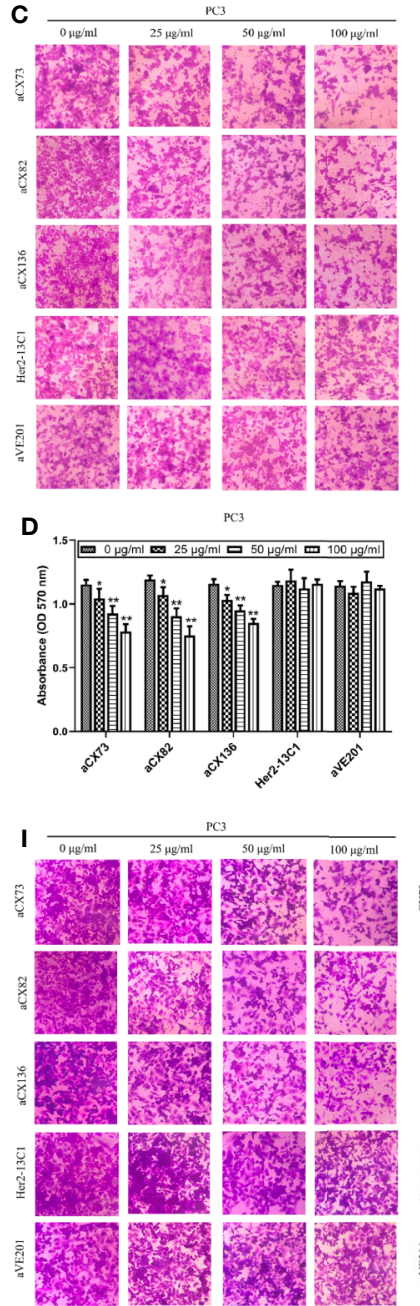

$\mathbf{J}$

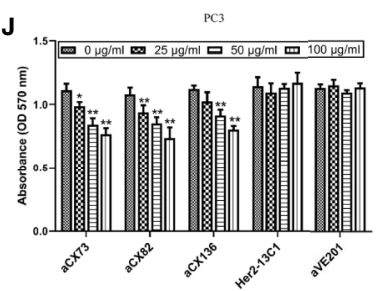

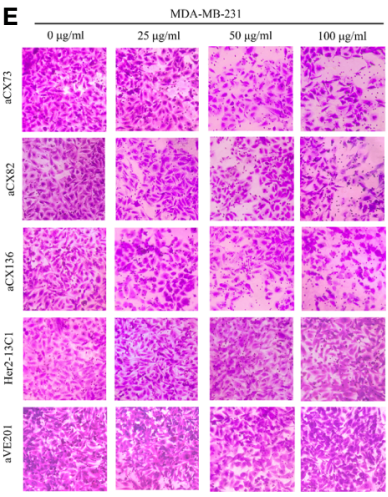
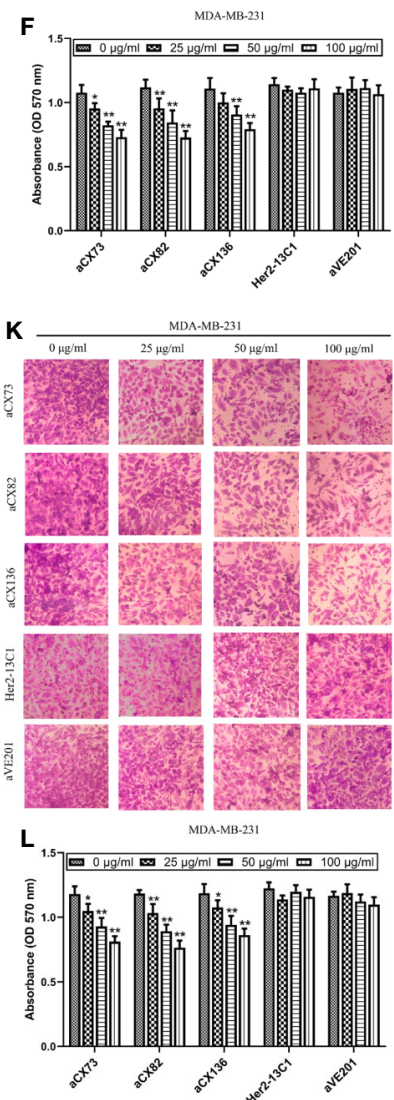

FIGURE 9 | Anti-CXCR4 scFvs can decrease cancer cell migration and invasion. To detect cell migration (A-F), cells were incubated with CXCL12 (100 ng/ml) and the anti-CXCR4 scFvs (aCX73, aCX82, and aCX136) or two negative control antibodies. The cells that crossed over the membrane were treated with crystal violet, which was solubilized in acetic acid. Optical density was detected. (A, B) DU145; (C, D) PC3; (E, F) MDA-MB-231. For the detection of cell invasion, matrigel was placed in transwells, and then, cells were added. (G, H) DU145; (I, J) PC3; (K, L) MDA-MB-231. The results represent mean \pm S.D $(\mathrm{n}=5)$. ${ }^{\star} P<0.05$ and ${ }^{\star \star} P<0.01$.

binding to and antagonizing Bcl-2 protein $(54,55)$. The p53 is a transcription factor that, when activated as part of the cell response to stress, regulates many downstream target genes including BAX. Caspases play an important role in the regulation of apoptosis signaling pathway. Caspase- 8 and 9 are the upstream initiator caspases which can trigger the activation of the downstream executioner caspases including caspases 3, 6, and 7 . These activated caspases cleave various cellular substrates and eventually lead to cell apoptosis $(56,57)$. As detected by flow cytometry, the induction of the pro-apoptotic proteins (Bax, ccaspase-3, and c-PARP-1) by the three scFvs was modest, ranging from 12.7 to $32.4 \%$ compared to the two negative control antibodies, ranging from 2.83 to $6.35 \%$ (Figures 5 and 6), while the results of Western blot analysis were more convincing than flow cytometry (Figure 7). This study demonstrates that the three anti-CXCR4 scFvs can induce cell 

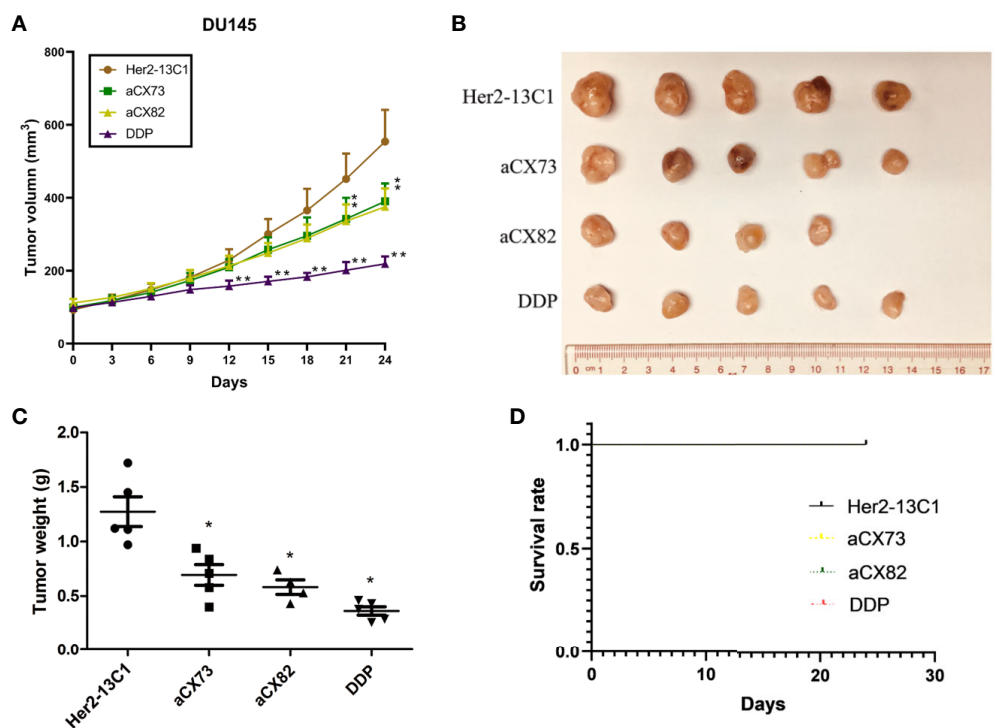

D

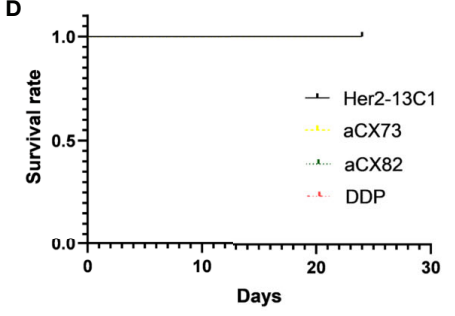

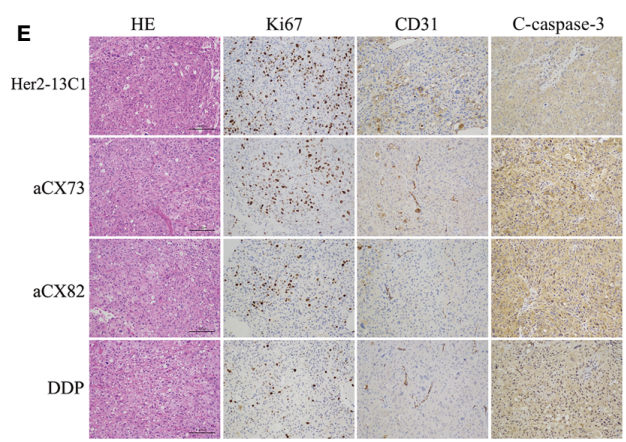

F

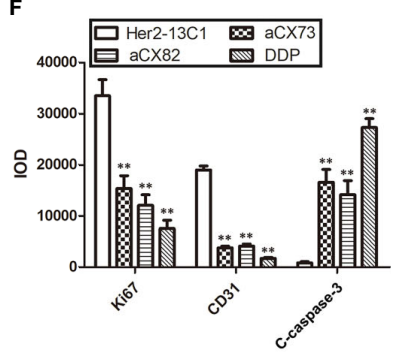

FIGURE 10 | Anti-CXCR4 scFvs can decrease DU145 xenograft growth. (A) Mice were inoculated with DU145 cells subcutaneously. Following tumors formation, mice were inoculated intravenously with the anti-CXCR4 scFvs (aCX73 and aCX82), the negative control antibody Her2-13C1 and DDP. (B, C) After euthanization of the mice on day 24 after the first inoculation, the tumors were excised. (D) The survival rates of mice treated with aCX73, aCX82, and DDP were determined compared to the negative control antibody Her2-13C1 using a log-rank (Mantel-Cox) test. Only the black line for the first group (Her2-13C1) was seen, and the other color lines for the other groups were invisible because all the color lines for all the groups were in the exact same position. (E) Tumor sections were incubated with HE or antibodies against Ki67, CD31 and c-caspase-3. (F) IOD was determined from Figure 10E. Results represent mean \pm S.D. ${ }^{\star} P<0.05$ and ${ }^{* \star} P<0.01$.

TABLE 1 | The risk of developing tumors in mice (hazard ratio) treated with the scFvs and DDP compared to the negative control antibody Her2-13C1 using a log-rank (Mantel-Cox) test.

\begin{tabular}{llcl}
\hline Group & N & HR & P value \\
\hline aCX73 & 5 & Undefined & $>0.9999$ \\
aCX82 & 4 & Undefined & $>0.9999$ \\
DDP & 5 & Undefined & $>0.9999$
\end{tabular}

$N$, the number of mice; HR, hazard ratio.

apoptosis of the three cancer cell lines by the regulation of apoptosis signaling pathway.

\section{DATA AVAILABILITY STATEMENT}

The datasets presented in this study can be found in online repositories. The names of the repository/repositories and accession number(s) can be found below: https://www.ebi.ac. uk/ena, LR743525 https://www.ebi.ac.uk/ena, LR743526 https:// www.ebi.ac.uk/ena, LR743527.

\section{ETHICS STATEMENT}

The animal study was reviewed and approved by the Institutional Animal Care and Use Committee of Jinan University.

\section{AUTHOR CONTRIBUTIONS}

HW and GC contributed to the conception and design of the study. G-QL, JL, X-XZ, Z-XL, and TC performed the experiments, analyzed the data, and drafted the manuscript. All authors contributed to manuscript revision and read and approved the submitted version. 


\section{FUNDING}

This work was supported by fund from the Science and Technology Program of Guangdong No. 2017A020211014 (H. Wei).

\section{REFERENCES}

1. Łukaszewicz-Zając M, Mroczko B, Szmitkowski M. Chemokines and their receptors in esophageal cancer-the systematic review and future perspectives. Tumor Biol (2015) 36(8):5707-14. doi: 10.1007/s13277-0153705-7

2. Weitzenfeld P, Ben-Baruch A. The chemokine system, and its CCR5 and CXCR4 receptors, as potential targets for personalized therapy in cancer. Cancer Lett (2014) 352(1):36-53. doi: 10.1016/j.canlet.2013.10.006

3. Yoshimura T. Discovery of IL-8/CXCL8 (The Story from Frederick). Front Immunol (2015) 6:278. doi: 10.3389/fimmu.2015.00278

4. Peng D, Cao B, Zhou YJ, Long YQ. The chemical diversity and structurebased evolution of non-peptide CXCR4 antagonists with diverse therapeutic potential. Eur J Med Chem (2018) 149:148-69. doi: 10.1016/ j.ejmech.2018.02.043

5. Figueras A, Alsina-Sanchis E, Lahiguera A, Abreu M, Muinelo-Romay L, Moreno-Bueno G, et al. A role for CXCR4 in peritoneal and hematogenous ovarian cancer dissemination. Mol Cancer Ther (2018) 17(2):532-43. doi: 10.1158/1535-7163.MCT-17-0643

6. Jang Y-G, Go R-E, Hwang K-A, Choi K-C. Resveratrol inhibits DHT-induced progression of prostate cancer cell line through interfering with the AR and CXCR4 pathway. J Steroid Biochem Mol Biol (2019) 192:105406. doi: 10.1016/ j.jsbmb.2019.105406

7. Katsura M, Shoji F, Okamoto T, Shimamatsu S, Hirai F, Toyokawa G, et al. Correlation between CXCR4/CXCR7/CXCL12 chemokine axis expression and prognosis in lymph-node-positive lung cancer patients. Cancer Sci (2018) 109(1):154-65. doi: 10.1111/cas.13422

8. Wald O. CXCR4 based therapeutics for non-small cell lung cancer (NSCLC). J Clin Med (2018) 7(10):303. doi: 10.3390/jcm7100303

9. Ahn JY, Seo K, Weinberg OK, Arber DA. The prognostic value of CXCR4 in acute myeloid leukemia. Appl Immunohistochem Mol Morphol (2013) 21 (1):79-84. doi: 10.1097/PAI.0b013e3182606f4d

10. Du Y, Long Q, Guan B, Mu L. Prognostic value of high CXCR4 expression in renal cell carcinoma: a system review and meta-analysis. Dis Markers (2015) 2015:568980. doi: 10.1155/2015/568980

11. Alterio CD, Portella L, Ottaiano A, Rizzo M, Carteni G, Pignata S, et al. High CXCR4 expression correlates with sunitinib poor response in metastatic renal cancer. Curr Cancer Drug Targets (2012) 12(6):693-702. doi: 10.2174/ 156800912801784820

12. Chatterjee S, Azad BB, Nimmagadda S. The intricate role of CXCR4 in cancer. Adv Cancer Res (2014) 124:31-82. doi: 10.1016/B978-0-12-411638-2.00002-1

13. Domanska UM, Kruizinga RC, Nagengast WB, Timmer-Bosscha H, Huls G, de Vries EG, et al. A review on CXCR4/CXCL12 axis in oncology: no place to hide. Eur J Cancer (2013) 49(1):219-30. doi: 10.1016/j.ejca.2012.05.005

14. Wong D, Kandagatla P, Korz W, Chinni SR. Targeting CXCR4 with CTCE9908 inhibits prostate tumor metastasis. BMC Urol (2014) 14:12. doi: 10.1186/ 1471-2490-14-12

15. Cojoc M, Peitzsch C, Trautmann F, Polishchuk L, Telegeev GD, Dubrovska A. Emerging targets in cancer management: role of the CXCL12/CXCR4 axis. Onco Targets Ther (2013) 6:1347-61. doi: 10.2147/OTT.S36109

16. Guo H, Ge Y, Li X, Yang Y, Meng J, Liu J, et al. Targeting the CXCR4/CXCL12 axis with the peptide antagonist E5 to inhibit breast tumor progression. Signal Transduct Target Ther (2017) 2:17033. doi: 10.1038/sigtrans.2017.33

17. Wadhawan A, Chatterjee M, Singh G. Present scenario of bioconjugates in cancer therapy: a review. Int J Mol Sci (2019) 20(21):5243. doi: 10.3390/ ijms20215243

18. Berning P, Schaefer C, Clemens D, Korsching E, Dirksen U, Potratz J. The CXCR4 antagonist plerixafor (AMD3100) promotes proliferation of Ewing sarcoma cell lines in vitro and activates receptor tyrosine kinase signaling. Cell Commun Signal (2018) 16(1):21. doi: 10.1186/s12964-018-0233-2

\section{ACKNOWLEDGMENTS}

We would like to thank the graduate students and technicians in the Cancer Therapy Group in Department of Cell Biology of Jinan University.

19. Miyata K, Takagi S, Sato S, Morioka H, Shiba K, Minamisawa T, et al. Suppression of Aggrus/podoplanin-induced platelet aggregation and pulmonary metastasis by a single-chain antibody variable region fragment. Cancer Med (2014) 3(6):1595-604. doi: 10.1002/cam4.320

20. Ghobrial IM, Liu CJ, Redd RA, Perez RP, Baz R, Zavidij O, et al. A phase Ib/II trial of the first-in-class anti-CXCR4 antibody Ulocuplumab in combination with lenalidomide or bortezomib plus dexamethasone in relapsed multiple myeloma. Clin Cancer Res (2020) 26(2):344-53. doi: 10.1158/1078-0432.CCR-19-0647

21. Fouquet G, Guidez S, Richez V, Stoppa AM, Le Tourneau C, Macro M, et al. Phase I dose-escalation study of F50067, a humanized anti-CXCR4 monoclonal antibody alone and in combination with lenalidomide and lowdose dexamethasone, in relapsed or refractory multiple myeloma. Oncotarget (2018) 9(35):23890-9. doi: 10.18632/oncotarget.25156

22. Ahamadi-Fesharaki R, Fateh A, Vaziri F, Solgi G, Siadat SD, Mahboudi F, et al. Single-chain variable fragment-based bispecific antibodies: hitting two targets with one sophisticated arrow. Mol Ther Oncolyt (2019) 14:38-56. doi: 10.1016/j.omto.2019.02.004

23. Zhang H, Wang X, Li X, Ma Z, Feng R. Construction, expression, and characterization of a single-chain variable fragment ( $\mathrm{ScFv}$ ) antibody targeting to the encephalomyocarditis virus. J Med Virol (2018) 90(7):118491. doi: 10.1002/jmv.25065

24. Farajnia S, Ahmadzadeh V, Tanomand A, Veisi K, Khosroshahi SA, Rahbarnia L. Development trends for generation of single-chain antibody fragments. Immunopharmacol Immunotoxicol (2014) 36(5):297-308 doi: 10.3109/08923973.2014.945126

25. Liu C, Kobashigawa Y, Yamauchi S, Toyota Y, Teramoto M, Ikeguchi Y, et al. Preparation of single-chain Fv antibodies in the cytoplasm of Escherichia coli by simplified and systematic chaperone optimization. J Biochem (2019) 166 (6):455-62. doi: 10.1093/jb/mvz059

26. Grieger E, Gresch G, Niesen J, Woitok M, Barth S, Fischer R, et al. Efficient targeting of CD13 on cancer cells by the immunotoxin scFv13-ETA' and the bispecific scFv [13xds16]. J Cancer Res Clin Oncol (2017) 143(11):2159-70. doi: $10.1007 / \mathrm{s} 00432-017-2468-5$

27. Fields S, Song O. A novel genetic system to detect protein-protein interactions. Nature (1989) 340(6230):245-6. doi: 10.1038/340245a0

28. Yuan Q, Huang L, Wang X, Wu Y, Gao Y, Li C, et al. Construction of human nonimmune library and selection of scFvs against IL-33. Appl Biochem Biotechnol (2012) 167(3):498-509. doi: 10.1007/s12010-012-9676-x

29. Nian S, Wu T, Ye Y, Wang X, Xu W, Yuan Q. Development and identification of fully human scFv-Fcs against Staphylococcus aureus. BMC Immunol (2016) 17(1):8. doi: 10.1186/s12865-016-0146-z

30. Ding L, Azam M, Lin YH, Sheridan J, Wei S, Gupta G, et al. Generation of high-affinity fully human anti-interleukin- 8 antibodies from its cDNA by twohybrid screening and affinity maturation in yeast. Protein Sci (2010) 19 (10):1957-66. doi: 10.1002/pro.484

31. Guo K, Feng G, Yan Q, Sun L, Zhang K, Shen F, et al. CXCR4 and CXCR3 are two distinct prognostic biomarkers in breast cancer: Database mining for CXCR family members. Mol Med Rep (2019) 20(6):4791-802. doi: 10.3892/ mmr.2019.10784

32. Liu Y, Ren CC, Yang L, Xu YM, Chen YN. Role of CXCL12-CXCR4 axis in ovarian cancer metastasis and CXCL12-CXCR4 blockade with AMD3100 suppresses tumor cell migration and invasion in vitro. J Cell Physiol (2019) 234 (4):3897-909. doi: 10.1002/jcp.27163

33. Du W, Lu C, Zhu X, Hu D, Chen X, Li J, et al. Prognostic significance of CXCR4 expression in acute myeloid leukemia. Cancer Med (2019) 8 (15):6595-603. doi: 10.1002/cam4.2535

34. Zhu WB, Zhao ZF, Zhou X. AMD3100 inhibits epithelial-mesenchymal transition, cell invasion, and metastasis in the liver and the lung through blocking the SDF-1 $\alpha /$ CXCR4 signaling pathway in prostate cancer. $J$ Cell Physiol (2019) 234(7):11746-59. doi: 10.1002/jcp.27831 
35. Yu X, Wang D, Wang X, Sun S, Zhang Y, Wang S, et al. CXCL12/CXCR4 promotes inflammation-driven colorectal cancer progression through activation of RhoA signaling by sponging miR-133a-3p. J Exp Clin Cancer Res (2019) 38(1):32. doi: 10.1186/s13046-018-1014-x

36. Zheng N, Chen J, Liu W, Liu J, Li T, Chen H, et al. Mifepristone inhibits ovarian cancer metastasis by intervening in SDF-1/CXCR4 chemokine axis. Oncotarget (2017) 8(35):59123-35. doi: 10.18632/oncotarget.19289

37. Li Y-P, Pang J, Gao S, Bai P-Y, Wang W-D, Kong P, et al. Role of CXCR4 and SDF1 as prognostic factors for survival and the association with clinicopathology in colorectal cancer: a systematic meta-analysis. Tumor Biol (2017) 39(6):1010428317706206. doi: 10.1177/1010428317706206

38. Cespedes MV, Unzueta U, Alamo P, Gallardo A, Sala R, Casanova I, et al. Cancer-specific uptake of a liganded protein nanocarrier targeting aggressive CXCR4(+) colorectal cancer models. Nanomedicine (2016) 12(7):1987-96. doi: 10.1016/j.nano.2016.04.003

39. Mendt M, Cardier JE. Activation of the CXCR4 chemokine receptor enhances biological functions associated with B16 melanoma liver metastasis. Melanoma Res (2017) 27(4):300-8. doi: 10.1097/CMR.0000000000000346

40. McConnell AT, Ellis R, Pathy B, Plummer R, Lovat PE, O’Boyle G. The prognostic significance and impact of the CXCR4-CXCR7-CXCL12 axis in primary cutaneous melanoma. Br J Dermatol (2016) 175(6):1210-20. doi: $10.1111 /$ bjd.14720

41. Uchida D, Onoue T, Kuribayashi N, Tomizuka Y, Tamatani T, Nagai H, et al. Blockade of CXCR4 in oral squamous cell carcinoma inhibits lymph node metastases. Eur J Cancer (2011) 47(3):452-9. doi: 10.1016/j.ejca.2010.09.028

42. Kuhne MR, Mulvey T, Belanger B, Chen S, Pan C, Chong C, et al. BMS936564/MDX-1338: a fully human anti-CXCR4 antibody induces apoptosis in vitro and shows antitumor activity in vivo in hematologic malignancies. Clin Cancer Res (2013) 19(2):357-66. doi: 10.1158/1078-0432.CCR-12-2333

43. Peng SB, Zhang X, Paul D, Kays LM, Ye M, Vaillancourt P, et al. Inhibition of CXCR4 by LY2624587, a fully humanized anti-CXCR4 antibody induces apoptosis of hematologic malignancies. PloS One (2016) 11(3):e0150585. doi: 10.1371/journal.pone.0150585

44. Pawig L, Klasen C, Weber C, Bernhagen J, Noels H. Diversity and interconnections in the CXCR4 chemokine receptor/ligand family: molecular perspectives. Front Immunol (2015) 6:429. doi: 10.3389/fimmu.2015.00429

45. Wu B, Chien EY, Mol CD, Fenalti G, Liu W, Katritch V, et al. Structures of the CXCR4 chemokine GPCR with small-molecule and cyclic peptide antagonists. Science (2010) 330(6007):1066-71. doi: 10.1126/science.1194396

46. Chevigne A, Fievez V, Szpakowska M, Fischer A, Counson M, Plesseria JM, et al. Neutralising properties of peptides derived from CXCR4 extracellular loops towards CXCL12 binding and HIV-1 infection. Biochim Biophys Acta (2014) 1843(5):1031-41. doi: 10.1016/j.bbamcr.2014.01.017

47. Chen LH, Huang Q, Wan L, Zeng LY, Li SF, Li YP, et al. Expression, purification, and in vitro refolding of a humanized single-chain Fv antibody against human CTLA4 (CD152). Protein Expr Purif (2006) 46(2):495-502. doi: $10.1016 /$ j.pep.2005.09.002
48. Sun H, Wu G, Chen Y, Tian Y, Yue Y, Zhang G. Expression, production, and renaturation of a functional single-chain variable antibody fragment (scFv) against human ICAM-1. Braz J Med Biol Res (2014) 47(7):540-7. doi: 10.1590/ 1414-431x20143276

49. Janthur W-D, Cantoni N, Mamot C. Drug conjugates such as antibody drug conjugates (ADCs), immunotoxins and immunoliposomes challenge daily clinical practice. Int J Mol Sci (2012) 13(12):16020-45. doi: 10.3390/ ijms131216020

50. Moradi-Kalbolandi S, Habibi-Anbouhi M, Golkar M, Behdani M, Rezaei G, Ghazizadeh L, et al. Development of a novel engineered antibody targeting human CD123. Anal Biochem (2016) 511:27-30. doi: 10.1016/ j.ab.2016.04.017

51. Zhou X, Qiu J, Wang Z, Huang N, Li X, Li Q, et al. In vitro and in vivo antitumor activities of anti-EGFR single-chain variable fragment fused with recombinant gelonin toxin. J Cancer Res Clin Oncol (2012) 138(7):1081-90. doi: 10.1007/s00432-012-1181-7

52. Maeda H, Nakamura H, Fang J. The EPR effect for macromolecular drug delivery to solid tumors: Improvement of tumor uptake, lowering of systemic toxicity, and distinct tumor imaging in vivo. Adv Drug Delivery Rev (2013) 65 (1):71-9. doi: 10.1016/j.addr.2012.10.002

53. Engl T, Relja B, Marian D, Blumenberg C, Müller I, Beecken W-D, et al. CXCR4 chemokine receptor mediates prostate tumor cell adhesion through $\alpha 5$ and $\beta 3$ integrins. Neoplasia (2006) 8(4):290. doi: 10.1593/ neo.05694

54. Gillies LA, Kuwana T. Apoptosis regulation at the mitochondrial outer membrane. . J Cell Biochem (2014) 115:632-40. doi: 10.1002/jcb.24709

55. Bagci EZ, Vodovotz Y, Billiar TR, Ermentrout GB, Bahar I. Bistability in apoptosis: roles of bax, bcl-2, and mitochondrial permeability transition pores. Biophys J (2006) 90:1546-59. doi: 10.1529/biophysj.105.068122

56. Ryu DS, Kim SH, Kwon JH, Lee DS. Orostachys japonicus induces apoptosis and cell cycle arrest through the mitochondria-dependent apoptotic pathway in AGS human gastric cancer cells. Int J Oncol (2014) 45:459-69. doi: 10.3892/ ijo.2014.2404

57. Yin Q, Park HH, Chung JY, Lin SC, Lo YC, da Graca LS, et al. Caspase-9 holoenzyme is a specific and optimal procaspase-3 processing machine. $\mathrm{Mol}$ Cell (2006) 22:259-68. doi: 10.1016/j.molcel.2006.03.030

Conflict of Interest: The authors declare that the research was conducted in the absence of any commercial or financial relationships that could be construed as a potential conflict of interest.

Copyright (c) 2020 Liang, Liu, Zhou, Lin, Chen, Chen and Wei. This is an open-access article distributed under the terms of the Creative Commons Attribution License (CC BY). The use, distribution or reproduction in other forums is permitted, provided the original author(s) and the copyright owner(s) are credited and that the original publication in this journal is cited, in accordance with accepted academic practice. No use, distribution or reproduction is permitted which does not comply with these terms. 